Universidad de Lima

Escuela de Posgrado

Maestría en Administración y Dirección de Negocios

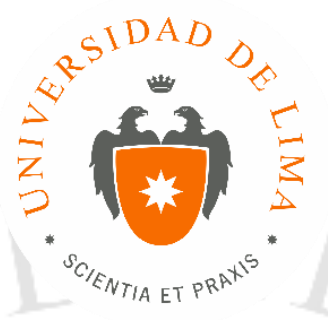

\title{
IMPLEMENTACIÓN DEL MODELO DE NEGOCIOS “TAMALÉATE"
}

Trabajo de investigación para optar al Grado Académico de Maestro en

Administración y Dirección de Negocios

\section{Lucciano Miguel Borgo Rivera}

Código 20162763

Jessica Jaherina Montellanos Montjoy

Código 20162765

Asesor: Edmundo Casavilca Maldonado

Lima - Perú

Diciembre de 2017 


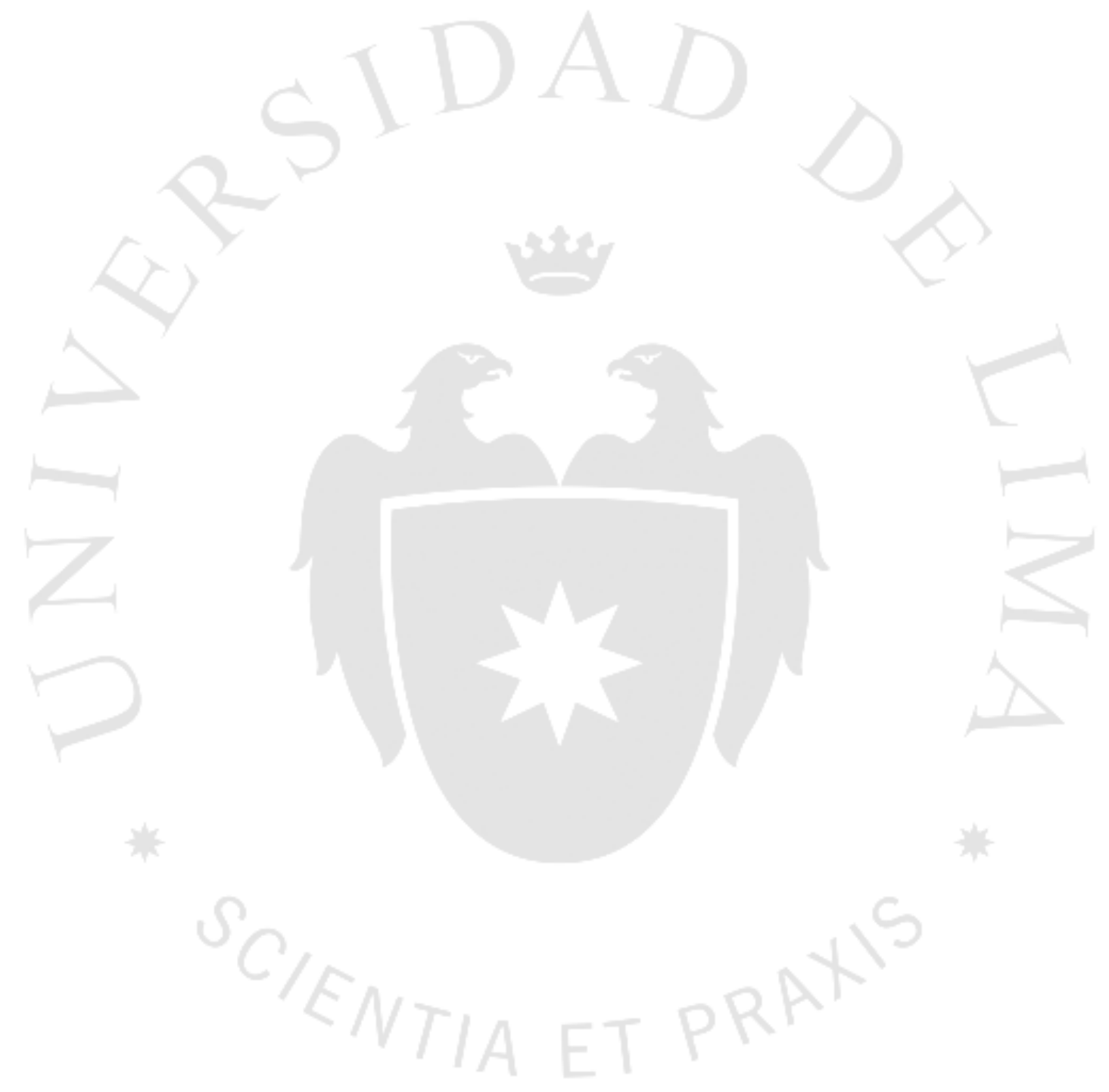




\section{IMPLEMENTACIÓN DEL MODELO DE NEGOCIOS “TAMALÉATE"}




\section{TABLA DE CONTENIDO}

\section{CAPÍTULO I: ASPECTOS GENERALES DEL NEGOCIO ...............................2}

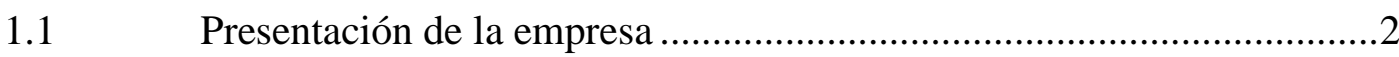

1.2 Marco teórico y mercado (benchmarking y mejores prácticas

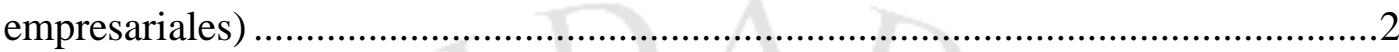

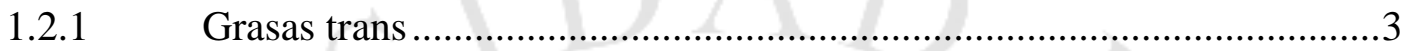

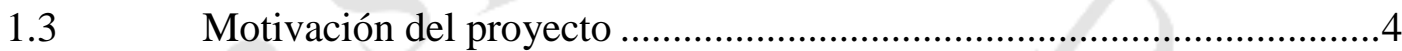

1.4 Percepción de la necesidad: análisis - problema - solución...................4

1.5 Descripción de la idea y la oportunidad .............................................

$1.6 \quad$ Justificación del atractivo de la propuesta ........................................6

1.7 Estrategia inicial y objetivos de alcance ..........................................6

1.8 Impacto comercial y responsabilidad social ....................................6

CAPÍTULO II: IDEA, INVESTIGACIÓN Y VALIDACIÓN DE LA

SOLUCIÓN .............................................................................................................7

2.1 Diseño y metodología de la investigación .........................................

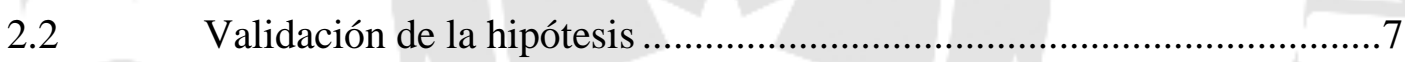

2.3 Validación de la solución............................................................

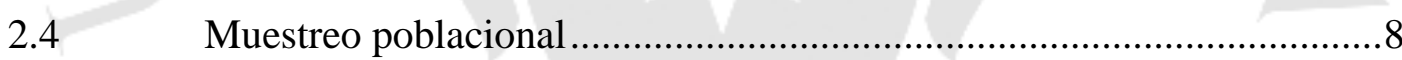

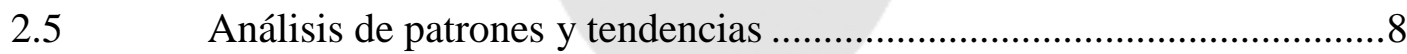

CAPÍTULO III: PLANEAMIENTO ESTRATÉGICO ....................................11

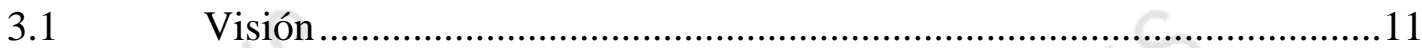

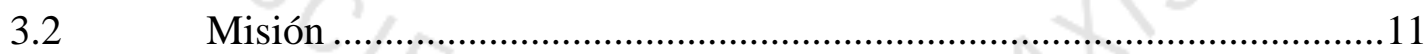

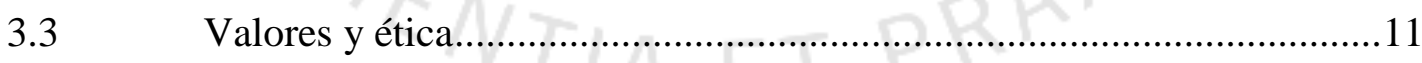

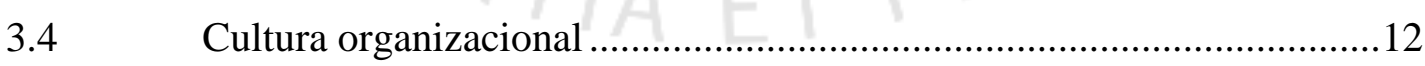

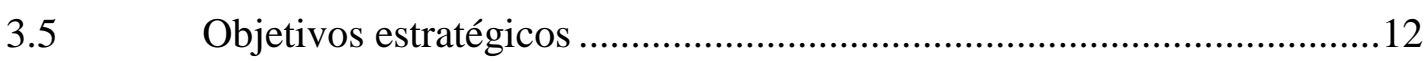

3.6 Análisis interno y externo (pestel) ....................................................13

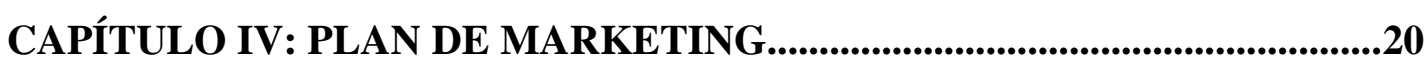

4.1 Planteamiento de objetivos generales de marketing ............................20

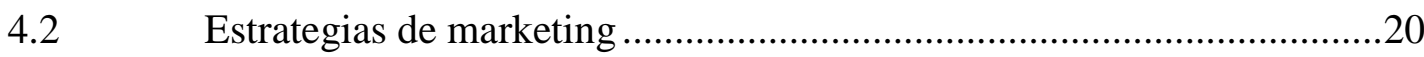

4.2.1 Segmentación y perfil del cliente.......................................................20 


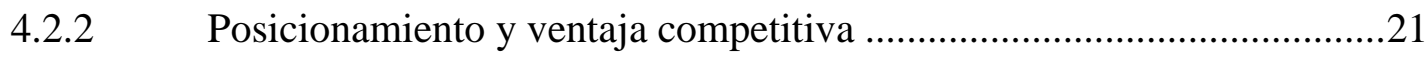

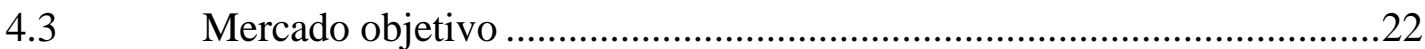

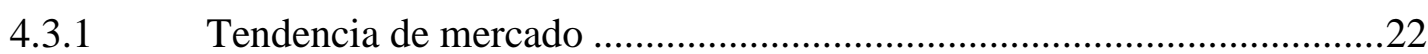

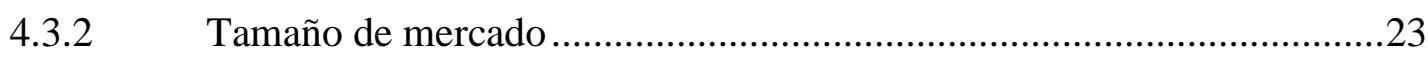

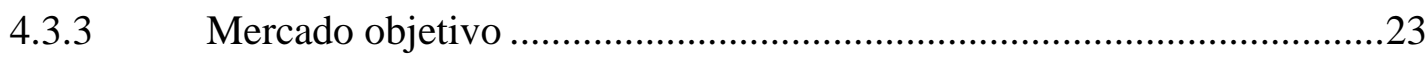

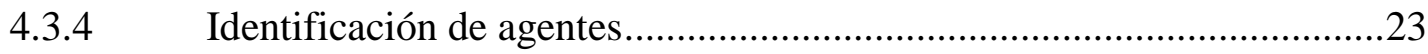

4.3.5 Potencial de crecimiento del mercado ..................................................24

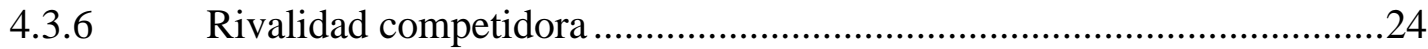

4.4 Desarrollo y estrategia del marketing mix .........................................25

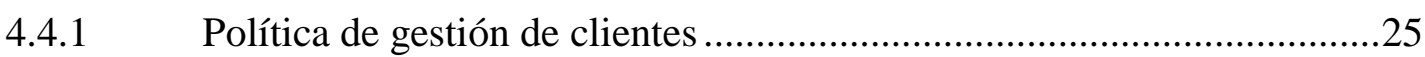

4.4.2 Estrategia de producto: especificaciones, calidad, variabilidad y

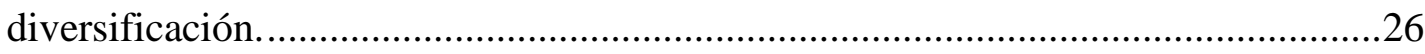

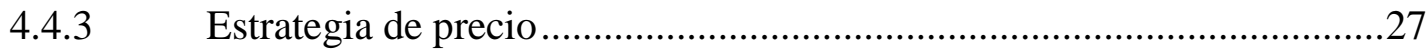

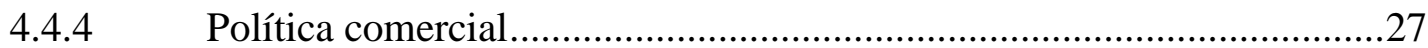

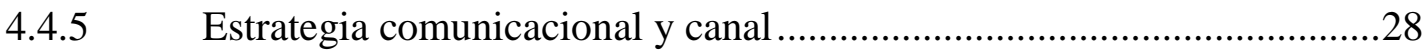

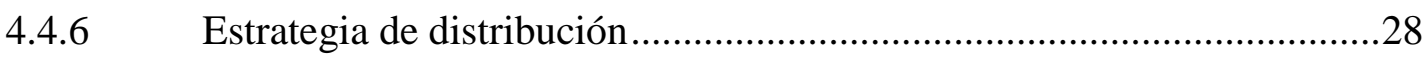

CAPÍTULO V: POLÍTICAS OPERACIONALES .................................................30

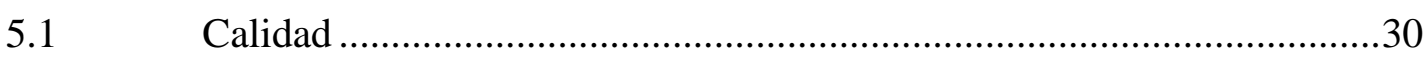

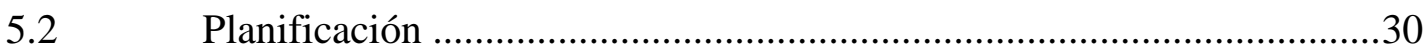

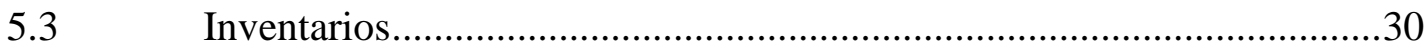

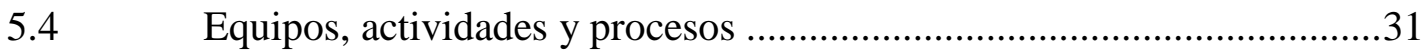

5.4.1 Diseño y capacidad de instalaciones ......................................................

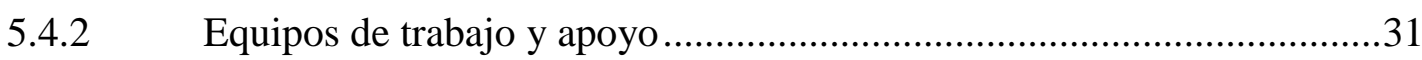

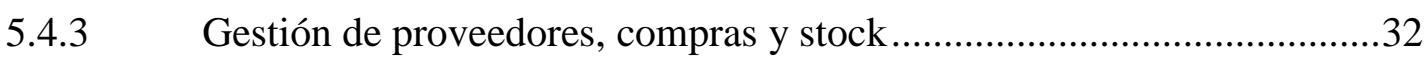

5.4.4 Tercerización o integración de procesos ...............................................32

CAPÍTULO VI: ESTRUCTURA ORGANIZACIONAL Y RECURSOS

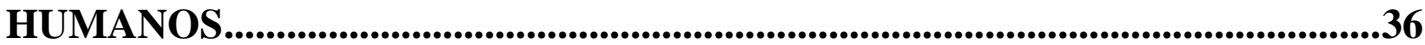

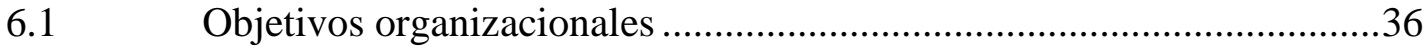

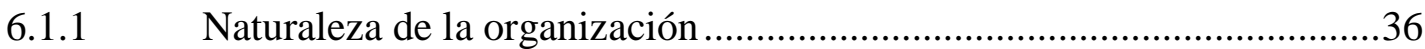

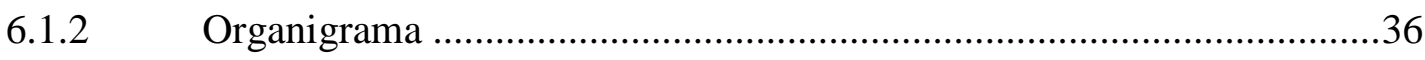

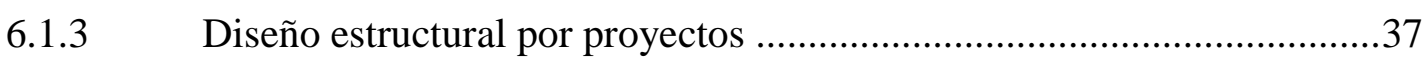

6.2 Diseño de puestos y responsabilidades ................................................37

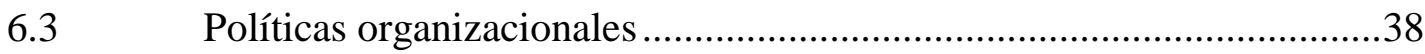

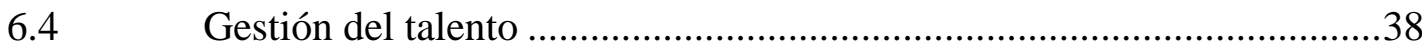




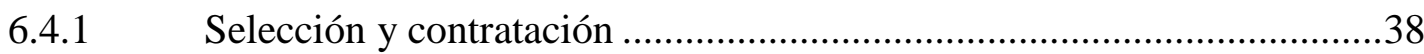

6.4.2 Remuneración y desempeño ............................................................38

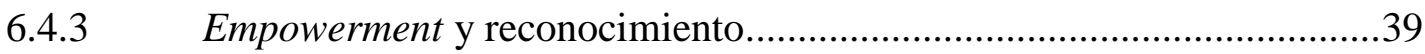

6.4.4 Capacitación, motivación y desarrollo .....................................................39

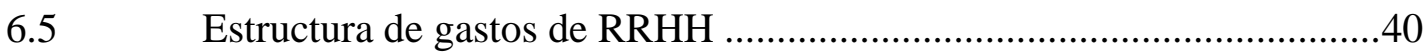

CAPÍTULO VII: PLAN ECONÓMICO - FINANCIERO .......................................41

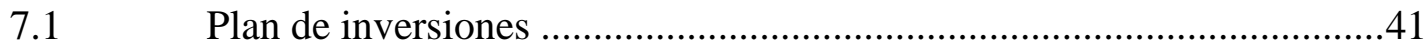

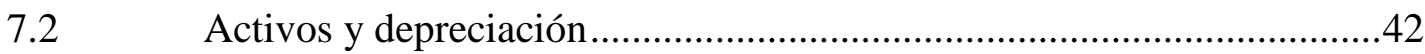

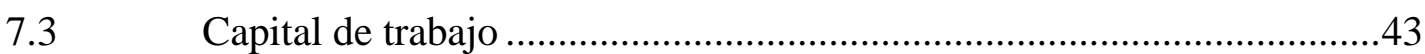

7.4 Fuentes de financiamiento y amortización ..........................................43

7.5 Balances previsionales (Balance general) ............................................45

7.6 Cuentas de explotación previsionales (GGPP) .....................................46

7.7 Proyección de ventas y Flujo de Tesorería (Cash flow) .........................46

7.8 Análisis de viabilidad y rentabilidad financiera...................................47

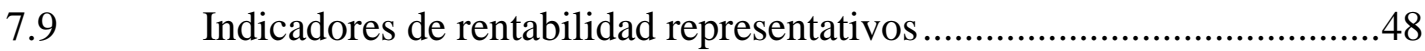

7.10 Análisis de riesgo y costo de oportunidad ..........................................50

7.11 Análisis por escenarios y gráficas ......................................................50

7.12 Principales riesgos del proyecto (cualitativos) ....................................53

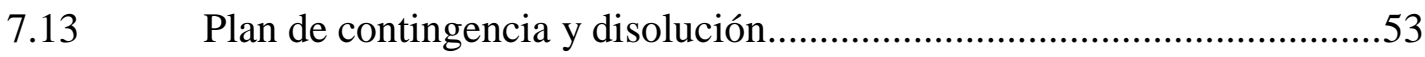

CONCLUSIONES Y RECOMENDACIONES...............................................55

REFERENCIAS ..........................................................................................................................56

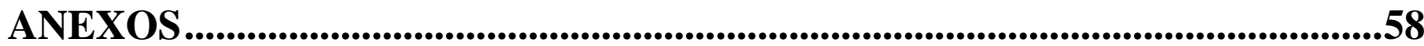




\section{ÍNDICE DE TABLAS}

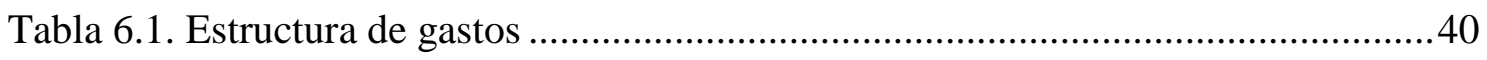

Tabla 7.1. Estructura de inversión ............................................................................ 41

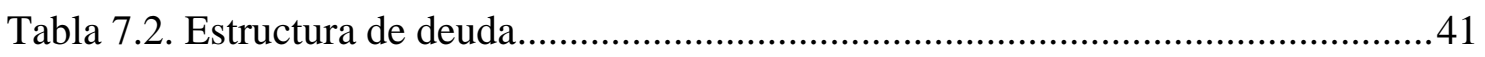

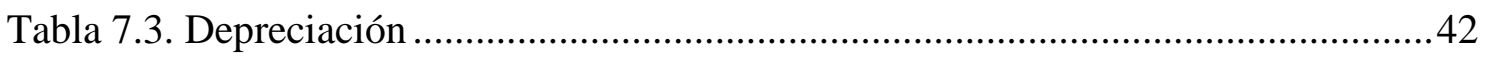

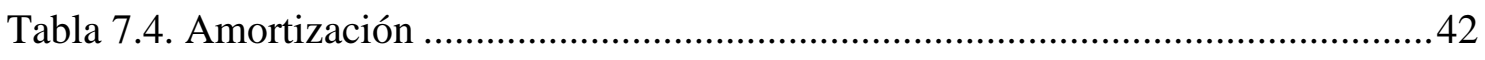

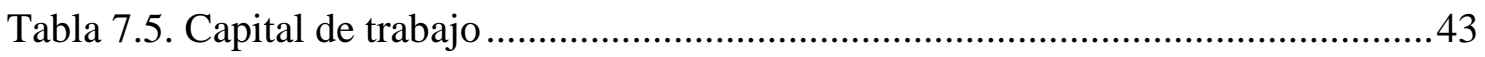

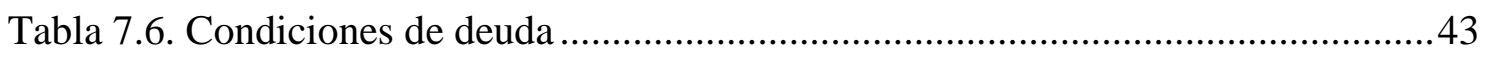

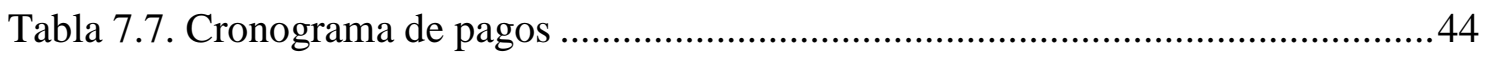

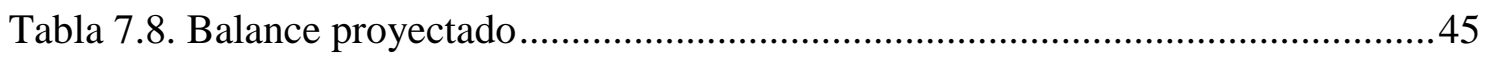

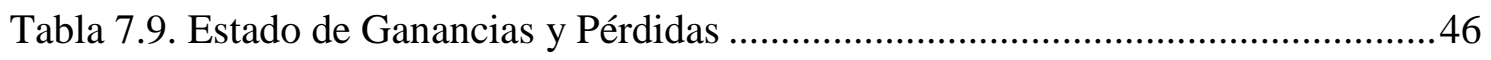

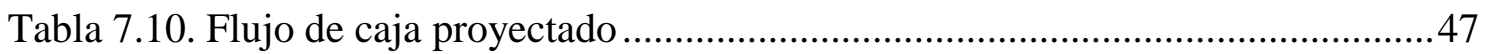

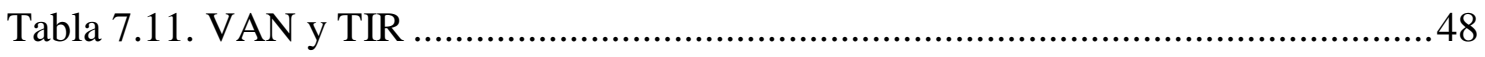

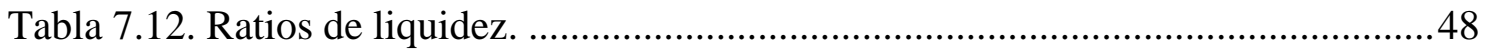

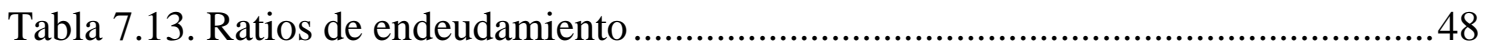

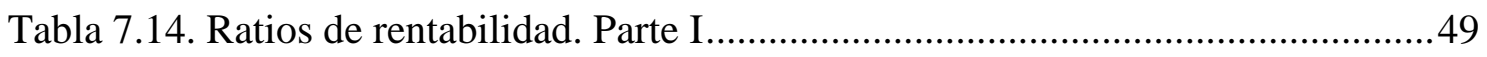

Tabla 7.15. Ratios de rentabilidad. Parte II ............................................................ 49

Tabla 7.16. Análisis de WACC mediante modelo KPM ................................................50

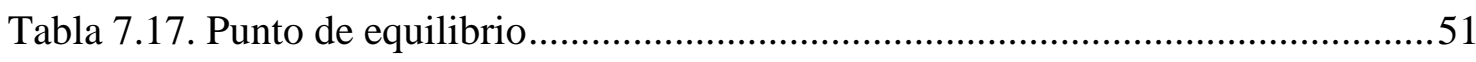

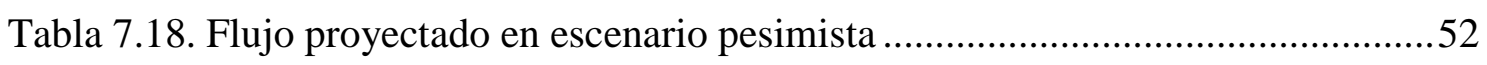

Tabla 7.19. Flujo proyectado en escenario optimista ..............................................52 


\section{ÍNDICE DE FIGURAS}

Figura 2.1. Modelo CANVAS ...¿Error! Marcador no definido.

Figura 3.1. Matriz de las 5 fuerzas de Porter ...¿Error! Marcador no definido.

Figura 3.2. Análisis FODA ¡Error! Marcador no definido.

Figura 4.1. Posicionamiento ¡Error! Marcador no definido.

Figura 4.2. Clientes ...¿Error! Marcador no definido.

Figura 4.3. Competidores ...¿Error! Marcador no definido.

Figura 5.1. Proveedores ¡Error! Marcador no definido.

Figura 5.2. Cadena de valor ¡Error! Marcador no definido.

Figura 5.3. Flujograma de la actividad ¡Error! Marcador no definido. Figura 5.4. Balanced Score Card ¡Error! Marcador no definido. Figura 6.1. Organigrama ¡Error! Marcador no definido. Figura 7.1. Punto de equilibrio ¡Error! Marcador no definido. 


\section{ÍNDICE DE ANEXOS}

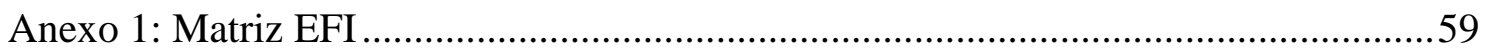

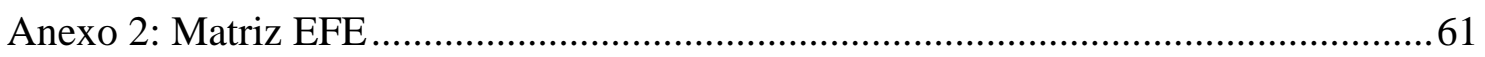

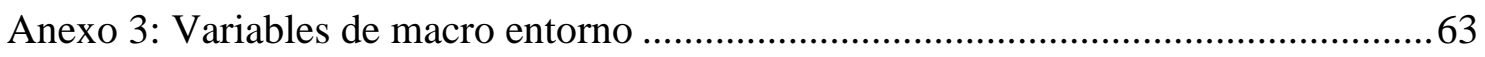




\section{RESUMEN EJECUTIVO}

El propósito de la tesis es la propuesta respecto a la implementación de un modelo de restaurante de comida rápida llamado "Tamaléate" con un concepto de stand up restaurant. El producto que se comercializará en este punto de venta es nuestro tradicional tamal que contará una innovación en las distintas combinaciones de rellenos aprovechando nuestra tan variada diversidad de sabores peruanos, así como también el auge que tiene nuestra gastronomía a nivel local y mundial.

Lo que pretendemos es posicionarnos como la primera opción en cuanto a comida rápida pero con una propuesta distinta a las que actualmente se encuentran en el mercado, como por ejemplo las hamburgueserías.

Luego del análisis elaborado se obtuvieron los siguientes indicadores:

- WAK: $27.68 \%$

- TIR: $91.30 \%$

- VAN: $731,622.77$

Por los antes mencionado, consideramos que el proyecto es viable ya que cuenta con buenos indicadores financieros.

Cabe resaltar, que Tamaléate es un proyecto pensado en ser socialmente responsable ya que en vez de desechar los productos que no se consuman durante el día estos serán donados a una ONG (Remar) que se encargará de alimentar a personas de bajos recursos. 


\section{CAPÍTULO I: ASPECTOS GENERALES DEL NEGOCIO}

\subsection{Presentación de la empresa}

Somos una empresa que brinda servicios de restauración bajo el concepto de stand up restaurant especializado en la venta de tamales con características únicas basadas en la fusión de sabores, a base de rellenos, con el fin de ofrecer a los comensales una novedosa opción de alimentación rápida, sabrosa y sin grasas saturadas.

\subsection{Marco teórico y mercado (benchmarking y mejores prácticas empresariales)}

Como nuestro negocio se centra principalmente en la venta de tamales, consideramos necesario definirlo.

Según el Diccionario de la Real Academia Española (2014), es: Especie de empanada de masa de harina de maíz, envuelta en hojas de plátano o de la mazorca del maíz, y cocida al vapor o en el horno. Las hay de diversas clases, según el manjar que se pone en su interior y los ingredientes que se le agregan.

Para el investigador gastronómico Patiño (2006):

El tamal condensa el sabor más auténtico de Latinoamérica, el que se rastrea desde el norte de México hasta la Patagonia. Tan íntimamente ligado a la tradición de los hispanoamericanos, que cada una de las repúblicas que lo conforman tiene en el tamal a "su” plato nacional. Y, desde luego, también a su más ancestral cocina. (párr. 2).

El tamal, por encima de todo, es hispanoamericano y símbolo de hermandad continental. Bienvenido el tamal que es parte de nuestra fiesta mestiza y de nuestra cultura criolla. (párr. 8).

En el ámbito nacional, el periodista Chaparro (2008), lo representa así:

Para muchos peruanos no hay domingo sin un tamalito en el desayuno. El tamal también es de ley si de comida criolla se trata. Con matices en su preparación, es popular en ciudades de la costa, sierra y selva. Lo devoran tanto en Comas como en La Planicie. (párr. 1). 
Es probable que mientras usted lea estas páginas tenga sobre la mesa familiar un suculento tamal que se alista a devorar con su infaltable pan francés y una humeante tacita de café. ¡Provecho! Pero después de disfrutar de ese placer dominical, con el que soñamos a lo largo de la semana, le recomendamos descubrir la historia culinaria de este platillo que es popular en cualquier estrato social del país. (párr. 2).

El tamal peruano puede estar en la mesa del hogar más humilde y en el comedor de la familia más pudiente. El tamal no conoce de clases sociales y tampoco conoce de límites ortodoxos en su preparación: a los clásicos tamales de chancho o pollo debemos añadir con admiración los que se hacen ahora con quinua, trigo, garbanzo y hasta de pulpa de cangrejo. (párr. 3).

Esta variedad no es casual. Un buen tamal se puede degustar en el desayuno o como una consistente 'entrada' a la hora del almuerzo y hasta en el "lonchecito". Es tal vez el alimento peruano al que más se recurre a cualquier hora del día y de la semana, por más que la tradición diga que son los sábados y domingos los días de su mayor consumo. (párr. 4).

\subsubsection{Grasas trans}

Actualmente, vivimos en una sociedad con un ritmo frenético de vida y con ello, ha proliferado la comida de rápida manufactura y de cómodo precio, a costa de componentes no tan buenos para la salud. Entre esos componentes mencionamos los que se denominan grasas trans.

¿Qué son las grasas trans?

Las grasas trans o también denominados ácidos grasos trans (AGT), surgen al convertir los aceites vegetales líquidos en grasas sólidas. Hay dos formas de obtener este tipo de grasas:

- Mediante un proceso químico natural que desarrollan microorganismos en el estómago de los rumiantes. Este supone un pequeño porcentaje del total de grasas trans consumidas.

- Mediante el proceso químico de hidrogenación, consistente en la transformación de aceites vegetales líquidos en grasas sólidas.

Con un consumo abundante y prolongado, este tipo de grasas se relacionan con patologías de ámbito cardiovascular, cáncer y elevados índices de colesterol LDL 
(popularmente conocido como colesterol "malo"), tal y como concluye la Universidad de Caldas (UCaldas, 2010).

Teniendo evidencias de que las grasas trans son nocivas para la salud, hemos desarrollado el proyecto de "Tamaléate" pensando en ofrecer a nuestros clientes un producto con tradición, rico, económico y sobretodo saludable, siguiendo la línea de la legislación peruana que encontramos en la Ley de Promoción de la Alimentación Saludable para Niños, Niñas y Adolescentes (2013):

Tiene como objeto la promoción y protección efectiva del derecho a la salud pública al crecimiento y desarrollo adecuado de las personas, a través de las acciones de educación, el fortalecimiento y fomento de la actividad física, la implementación de kioscos y comedores saludables, en las instituciones de educación básica regular y la supervisión de la publicidad y otras prácticas relacionadas con los alimentos, bebidas no alcohólicas dirigidas a niños, niñas y adolescentes para reducir y eliminar las enfermedades vinculadas con el sobrepeso, la obesidad y las enfermedades crónicas conocidas como no transmisibles.

\subsection{Motivación del proyecto}

- Es único

- Desarrollo de innovación disruptiva en la gastronomía peruana (fusión de sabores)

- Proyecto accesible y realizable.

- El problema: la gente no tiene tiempo

\subsection{Percepción de la necesidad: análisis - problema - solución}

- Análisis: la oferta de comida rápida está aglomerada de productos que contienen altos índices de grasas saturadas y grasas trans, con poca variedad de lo ofrecido en el mercado; cabe resaltar que los tiempos de servicio son elevados.

- Problema: actualmente no existe un alimento que sea rápido y que no contenga grasas saturadas y grasas trans. 
- Solución: "Tamaléate", nuevo concepto de stand up restaurant que ofrece una fusión de sabores en los rellenos de tamales contundentes al paso.

\subsection{Descripción de la idea y la oportunidad}

Hoy en día existen conceptos de restaurantes que ofrecen alimentos de forma rápida para personas con tiempo limitado. Sin embargo, la oferta actual no contempla brindar alimentos sin grasas saturadas y sin grasas trans y a pesar de estar dentro de los fast food, los tiempos de servicio son elevados. Cabe resaltar que la gama de estos productos es limitada.

Es por ello que basándonos en lo antes mencionado consideramos ofrecer este nuevo concepto con el fin de satisfacer las necesidades insatisfechas.

Actualmente existen 419 locales de fast food en Lima y Callao así como 138 en provincias. Cabe resaltar que, "según el Instituto Nacional de Estadística e Informática (INEI), el Perú al 2015 , tiene 31 millones 488,625 habitantes y esta cifra va en incremento año a año"(INEI:2015). Adicionalmente, esta ciudad tiene un abundante movimiento en el sector laboral ya que la mayoría de sedes de las principales empresas se encuentran ubicadas ahí.

Muchos ciudadanos viven su día a día a merced del trabajo la mayoría de los días de la semana, teniendo poco tiempo para poder pasar el tiempo con su familia y poder preparar sus alimentos, por ello muchas personas solicitan servicios de los locales de comida rápida, denominados fast food.

Más del 70\% de limeños acude cada quince días a este tipo de establecimientos, siendo los jóvenes los que acuden con más frecuencia. La asistencia a estos locales es mayor en el almuerzo que en la cena.

Un estudio publicado en el año 2015 por Mapcity.com, empresa especializada en geobusiness intelligence para Latinoamérica, identificó 557 locales de comida rápida en el Perú. Según este estudio, Kentucky Fried Chicken encabeza la lista con 84 establecimientos seguido de Pizza Hut con 66, Bembos con 57, Mc Donalds con 54 y otras 10 cadenas más que tienen entre 37 y 11 sucursales.

Este estudio precisa que en Lima y Callao se pueden encontrar 419 locales de fast food y 138 en provincias. 
El gasto mensual por consumidor es de S/. 64. El 46\% de los consumidores acuden a los fast food en la hora del almuerzo y un $43 \%$ en la cena.

Este año en el Perú tienen una rentabilidad del 20\% con ventas de US\$ 700 millones según estimaciones de Front Consulting.

Las estrategias de segmentación han mejorado y se han expandido a nivel nacional, las cadenas de alta rentabilidad con las cadenas de hamburguesas y pollo broaster, con una rentabilidad de $10 \%$ a $20 \%$.

\subsection{Justificación del atractivo de la propuesta}

Nuestra propuesta consiste en ofrecer tamales con fusión de sabores (rellenos) a un precio, en combo, de S/. 12.90, con alta accesibilidad (zonas geográficas) de rápida atención, presentación (manos limpias) y rellenos triturados para la mejor difusión de sabores con un práctico consumo.

La ubicación de Tamaléate será estratégica: en los principales centros comerciales, iniciando operaciones en el centro comercial Jockey Plaza.

Nuestro modelo de negocio es escalable, es decir, en función a las ventas, con la colocación de un restaurante en un periodo no mayor a 3 años.

\subsection{Estrategia inicial y objetivos de alcance}

- Ubicación estratégica.

- Fusión de sabores (diferenciación).

- Presentación (diferenciación).

- Tiempos de servicio (rapidez real).

\subsection{Impacto comercial y responsabilidad social}

- Nueva alternativa de selección.

- Revalorizar la historia y tradición del tamal.

- Impactar de manera positiva en el desarrollo de la gastronomía peruana 
- Proveedor de rehabilitación de mermas.

\section{CAPÍTULO II: IDEA, INVESTIGACIÓN Y VALIDACIÓN DE LA SOLUCIÓN}

\subsection{Diseño y metodología de la investigación}

La metodología a utilizar en la investigación será la Transversal. Esta será llevada a cabo mediante entrevistas a profundidad realizadas al público objetivo, las cuales serán extrapoladas a una población infinita. Estas entrevistas serán reforzadas con dos focus group los cuales serán realizados a personas que se encuentren entre rangos de edades de 25 a 50 años con diferencia de 5 años entre cada persona.

\subsection{Validación de la hipótesis}

Hipótesis de Investigación (Hi): en base a la propuesta de negocio hay que determinar, de la muestra a utilizar, todos aquellos usuarios que están interesados en tomar el servicio y/o producto. Es decir, el nivel de aceptación.

Se está eligiendo este método debido a que actualmente no existe en el mercado un establecimiento y/o concepto que pueda ofrecer a los comensales este tipo de estándares los cuales queremos ofrecer; hay mucho de lo mismo en cuanto a lugares de comida rápida. Es por ello que nos vemos en la necesidad de investigar esta problemática con el fin de determinar lo que los usuarios desean a pesar de que ellos aún no lo sepan.

“Tamaléate" será la alternativa deseada por el consumidor para poder cubrir la necesidad de un producto que no contenga grasas saturadas ni grasas trans en rápidas fracciones de tiempo.

\subsection{Validación de la solución}


Para validar la solución del problema se realizarán entrevistas a profundidad que contendrán preguntas de tipo cerradas y abiertas sucesivamente, de las cuales se desprenderá $\quad$ información del tipo $\quad$ cualitativo. Esta información será contrastada con los resultados obtenidos del focus group.

\subsection{Muestreo poblacional}

El método a utilizar será el muestreo inverso el cual se realiza haciendo un análisis de la demanda insatisfecha y se toma un porcentaje de esta para analizar la probabilidad de éxito y el tamaño de mercado potencial.

\subsection{Análisis de patrones y tendencias}

Mega tendencia de nuevos sabores y colores en la comida: la mezcla cultural también traerá la predilección por la fusión de sabores en un mismo plato, sabores fuertes y contrastantes, en cuanto a los colores que antes no se contemplaban dentro de los platos serán los que se encontrarán en boga.

Tendencia de consumo de producto nacional: el nacionalismo es una tendencia que viene creciendo año a año y que impacta directamente en todos los negocios que tienen capital nacional.

Mega tendencia de comida peruana y fusión del mundo: hoy la comida peruana es considerada la mejor del mundo y es por eso que el tema de fusión de sabores se compenetra con esta, convocando a mayor cantidad de clientes y consumidores.

Tiempo limitado en la vida cotidiana de las personas: el no tener tiempo para poder alimentarnos es una oportunidad de negocio, el cual beneficia directamente al negocio a implementar. 
Figura 2.1

Modelo CANVAS

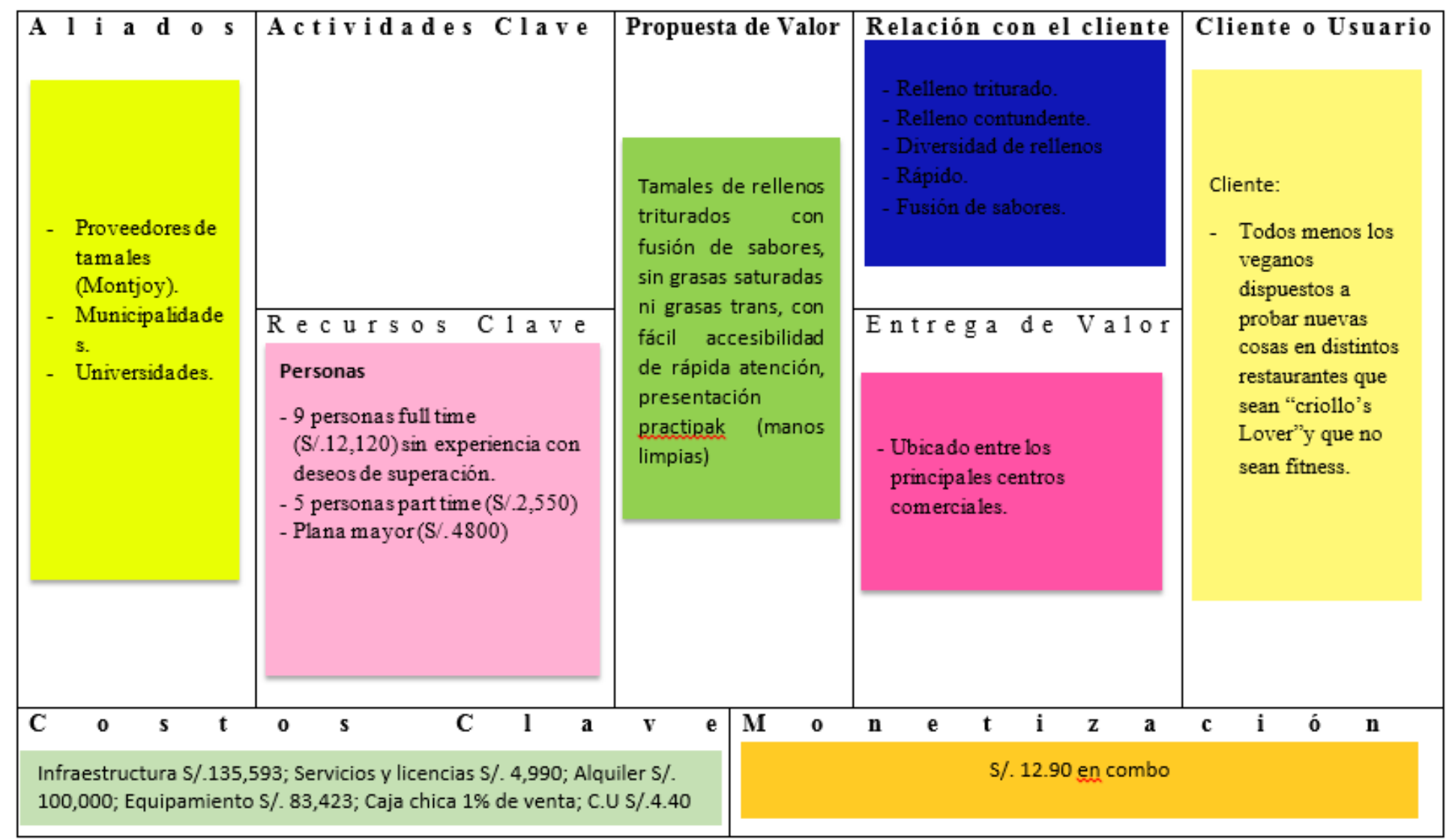

Elaboración propia. 


\section{CAPÍTULO III: PLANEAMIENTO ESTRATÉGICO}

\subsection{Visión}

Ser los mejores operadores de comida brindando una experiencia increíblemente satisfactoria con una fusión única de sabores.

\subsection{Misión}

Somos los impulsores de la gastronomía peruana innovando en sabores y con tiempos de servicio precisos.

\subsection{Valores y ética}

- Desarrollo conjunto: crecimiento y progreso para cada una de las partes involucradas. Accionistas, colaboradores y proveedores.

- Igualdad: brindamos un trato amable y cercano a todo aquel con el que nos relacionamos. Evitando cualquier tipo de actitud que pueda ofender o incomodar a la otra persona.

- Respeto: formar un ambiente de trabajo alegre en donde prime el respeto por nuestros miembros de equipo y la dignidad de cada una de las personas.

- Solidaridad: ser el pilar de cada uno nuestros colaboradores, apoyándonos mutuamente para el crecimiento de cada uno.

- Conciencia social: formamos parte de nuestra sociedad y por tanto somos responsables de contribuir a mejorar nuestro entorno social y ambiental.

- Reciprocidad: saber reconocer lo que el entorno nos brinda para pagarle con creces. 


\subsection{Cultura organizacional}

Sabemos que la cultura organizacional es lo que queremos expresar y generar dentro de nuestra organización. Nosotros deseamos que nuestros colaboradores se sientan como en casa y tengan el chip de querer nuestras tradiciones y valorar nuestro país dándole el toque de modernidad que buscamos materializar en nuestro producto. Asimismo, buscamos que todos nos sintamos parte de un equipo en donde la contribución que aporte cada uno sea vital para la continuidad y el éxito de nuestro proyecto. Todo lo antes mencionado va de la mano de nuestros valores descritos en el punto anterior.

\subsection{Objetivos estratégicos}

- Generar rentabilidad en nuestro negocio para asegurar el éxito de cada uno de los integrantes de esta organización en futuro cercano - clientes, accionistas, colaboradores y proveedores.

- Posicionar "Tamaléate" en la mente del consumidor como una opción diferente. Mejor preparado, con más variedad y más sabroso.

- En el muy corto plazo, primer año de operación: consolidar nuestros productos y servicios, logrando uniformidad en cada transacción.

- En el mediano plazo, próximos cuatro años, abrir el tercer stand up restaurant en Lima, atacando principalmente al público en general a excepción de los veganos.

- En el largo plazo, próximos 10 años: expandir la marca a nivel nacional, abriendo nuestra oferta al NSE B-C mediante modelos replicables como el de una franquicia.

- Brindar a nuestros colaboradores la posibilidad de desarrollarse a nivel profesional y personal, permitiéndoles mejorar su calidad de vida. Poner a su disposición una estructura organizacional que les brinde la oportunidad de querer mejorar. Fomentar la capacitación y el desarrollo de sus aptitudes.

- Contribuir con nuestra sociedad generando aportes de manos de nuestros propios colaboradores, en comunidades más necesitadas. Con el objetivo de marcar un cambio en quienes nos reciban y en nosotros mismos. 


\subsection{Análisis interno y externo (pestel)}

\subsubsection{Variables políticas}

- Política de impuestos: el impacto que genera un cambio en los impuestos afecta directamente al consumidor por ende a la empresa pues va a modificar el precio de venta.

- Políticas salariales: el posible aumento del salario mínimo vital afectara los recursos económicos de la empresa y a su vez hará que se modifiquen las proyecciones destinadas a la mano de obra.

- Inestabilidad política: modificación y derogación de leyes que afecten directamente al consumidor o al micro empresario.

- Elecciones municipales 2018: creación de nuevos regímenes o barreras de entrada en el municipio.

\subsubsection{Variables económicas.}

- PBI: este indicador nos va a decir cuál es el crecimiento económico per capita de nuestros consumidores, lo cual permitirá que tenga mayor disposición de dinero para gastar.

- Porcentaje de población económicamente activa: forma parte de nuestro mercado objetivo y la probabilidad de crecimiento del mercado del negocio.

- Tasas de interés.

- Inflación: la devaluación de la moneda impacta de manera negativa pues la pérdida de valor hará que el mercado optimice sus gastos y no se vea.

\subsubsection{Variables socioculturales}

- Mega tendencia de nuevos sabores y colores en la comida: la mezcla cultural también traerá la predilección por la fusión de sabores en un mismo plato, 
sabores fuertes y contrastantes, en cuanto a los colores que antes no se contemplaban dentro de los platos serán los que se encontrarán en boga.

- Tendencia de consumo de producto nacional: el nacionalismo es una tendencia que viene creciendo año a año y que impacta directamente en todos los negocios que tienen capital nacional.

- Mega tendencia de comida peruana y fusión del mundo: hoy la comida peruana es considerada la mejor del mundo es por eso que el tema de fusión de sabores se compenetra con está, convocando a mayor cantidad de clientes y consumidores.

- Tiempo limitado en la vida cotidiana de las personas: el no tener tiempo para poder alimentarnos es una oportunidad de negocio, el cual beneficia directamente al negocio.

\subsubsection{Variables tecnológicas}

- Nuevas tecnologías aplicadas a la restauración: facilitación y automatización de procesos que generan más eficiencia en la operación.

\subsubsection{Variables ecológicas}

- Fenómeno del niño: impacta negativamente en los costos de la materia prima.

- Cambio climático y contaminación: genera que las formas de cosecha y siembra varíen, esto podría generar incremento en costo y a su vez cambio de sabores.

- Conciencia por el reciclaje.

\subsubsection{Variables legales}

- Nuevas regulaciones de digesa: las nuevas regulaciones podrán ejercer mayor presión y búsqueda de excelencia en las operaciones lo cual genera costos ocultos. 
Figura 3.1

Matriz de las 5 fuerzas de Porter

$\checkmark$ Respecto a nuestro proveedores de tamales,

"tamaléate" tendría una relación de dependencia ya que el fabricante tiene un lazo familiar con uno de los socios.

En el mediano plazo se contará con un proveedor

adicional con el fin de asegurar el abastecimiento del

\begin{tabular}{|l|}
\multicolumn{1}{|c|}{ PROVEEDORES } \\
- Corp. Montjoy (fabricante de \\
tamales) \\
- Suministros \\
- Imprenta
\end{tabular}

En cuanto a los sustitutos, existe una gran variedad de productos similares que nuestro potencial cliente

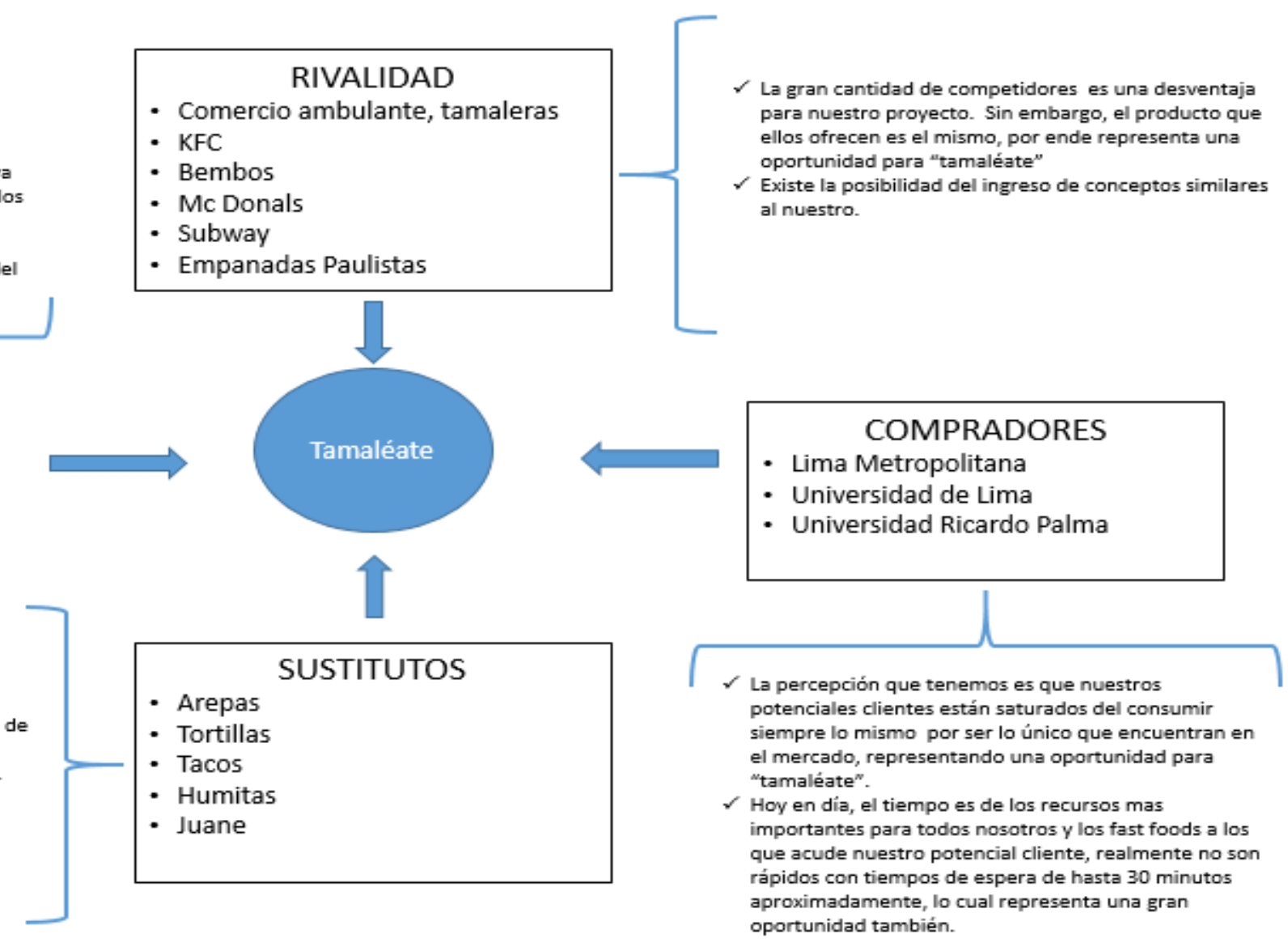

Elaboración propia. 
3.7 Análisis sectorial e Identificación de riesgos y amenazas. Análisis FODA.

\subsubsection{Fortalezas}

- Variedades de sabores.

- No contiene grasas saturadas ni grasas trans.

- Listo para consumir.

- No hay línea de producción.

- Buena calidad del producto.

- Es un producto innovador en el mercado.

- Producto con el sello de la marca Perú.

- $\quad$ Nueva propuesta de alimentación al paso.

- Nuevo concepto de restaurante stand up.

\subsubsection{Debilidades}

- Falta de publicidad.

- Marca no conocida en los segmentos.

- Un solo tamaño de presentación.

- Recursos económicos limitados.

- Cartera de productos limitada.

\subsubsection{Oportunidades.}

- Mayor poder adquisitivo.

- Aumento de empleo.

- Mayor diversidad de canales de comunicación.

- Mayores vías de acceso al interior.

- Mayor cantidad de TLC. 
- Tiempo limitado.

- Tendencia a no comer grasas saturadas ni grasas trans.

- Tendencia comer productos peruanos.

- Nuevas técnicas de regadío.

\subsubsection{Amenazas}

- Precio de combustible.

- Inestabilidad política.

- Fenómenos climáticos inesperados.

- Alta competencia en el mercado.

- Es un producto del tipo elástico.

- Plagio de receta y/o producto. 
Figura 3.2

Anál

isis FODA

\section{OPORTUNIDADES}

O1 Mayor poder adquisitivo

O2 Aumento del empleo

O3 Mayores diversidad de canales de comunicación

O4 Mayor vías de acceso al interior

O5 Mayor cantidad de TLC

O6 Tiempo limitado

07 Tendencia a no consumir grasas saturadas ni grasas tran

O8 Tendencia a consumir los productos peruanos

O9 Nuevas técnicas de regadio

A1 Precio de combustible

A2 Inestabilidad política

A3 Fenómenos climáticos inesperados

A4 Alta competencia en el mercado

A5 Es un producto del tipo elístico

A6 Plagio de receta $\mathrm{y} / \mathrm{O}$ producto

\section{FORTALEZAS}

\section{F1 Variedad de sabores}

F2 No contiene grasas saturadas ni grasas trans

F3 Listo para consumir

F4 No hay línea de producción

F5 Buena calidad del producto

F6 Es un producto innovador en el mercado

F7 Producto con el sallo marca Perú

F8 Nueva propuesta de alimentación al paso

F9 Nuevo concepto de restaurante stand up

\section{DEBILIDADES}

D1 Falta de publicidad

D2 Marca no conocida por los segmentos medios

D3 Un solo tamaño de presentación

D4 Recursos económicos limitados

D5 Cartera de productos limitada

ESTRATEGIAS DO

1) Precios nivelados contra la competencia

(F1/F5/F6-01/O2/O6)

2) Proceso de regionalización de tamaléate (F1/F5/F6-O4)

3) Modulo de compra wrap and go ( $F 3 / F 6 / F B / F 9-O 6)$

4) Comunicación de producto nacional cómprale al Perú

(F7-08)

1) Renegociar con el proveedor precios (D4-04/O9)

2) Creación de línea, con tu propio relleno

(D5-07/OB]

3) Impulso de productos no grasas saturadas no grasas

trans mediante las redes sociales (D1/D4-O7)

\section{ESTRATEGIAS FA}

\section{ESTRATEGIAS DA}

1) Negociación con proveedores para que el precio de los

tamales incluva la distribución de los mismos a cada

punto de venta (F4/F6-A1)

2) Patentar receta y proceso de producción para uso

1) 5 acar una línea de diferente tamaño de porciones

con diferentes precios (D3/D4/D5-A4/A5)

2) Asegurar un precio medio con el proveedor con un

derivado financiero ( $D 5-A 3)$ 
Elaboración propia. 


\section{CAPÍTULO IV: PLAN DE MARKETING}

\subsection{Planteamiento de objetivos generales de marketing}

- Dar a conocer la marca en el corto plazo (1 año).

- Estandarizar los procesos de servicio (1 año).

- Obtener una rentabilidad prefijada de nuestra inversión.

- Determinar una meta que esté de acuerdo con la capacidad instalada de la empresa.

\subsection{Estrategias de marketing}

Basados en el FODA así como también en los segmentos a los que nos vamos a dirigir, utilizaremos las estrategias por diferenciación ya que nuestro producto pertenece a un mercado en madurez y necesita ofrecer una propuesta distinta a las existentes en el mercado.

\subsubsection{Segmentación y perfil del cliente}

\subsubsection{Variables para la micro segmentación}

\section{Beneficios buscados}

- Rellenos triturados.

- Fusión de sabores.

- Fácil accesibilidad.

- Rápida atención.

- Presentación practipak (manos limpias). 


\section{Variables socio económicas}

- Nivel socio económico A, B y C.

- Personas económicamente activas.

\section{Variables demográficas}

- Edad (25 - 55 años).

- Familias en general.

\section{Variables psicográficas}

- No veganos.

- Criollo lovers

- No fitness.

- Early food adopters.

\section{Variables geográficas}

- Miraflores, San Isidro, San Borja, Surco, La Molina.

\subsubsection{Posicionamiento y ventaja competitiva}

"Tamaléate" cuenta con un producto único en su clase desde la presentación del tamal hasta la variedad de sabores, adicional a esto apelamos a la fusión de platos típicos del Perú que hoy por hoy no han sido contemplados dentro de la gama de rellenos que se toma en cuenta para este snack regional. 
Figura 4.1

Posicionamiento

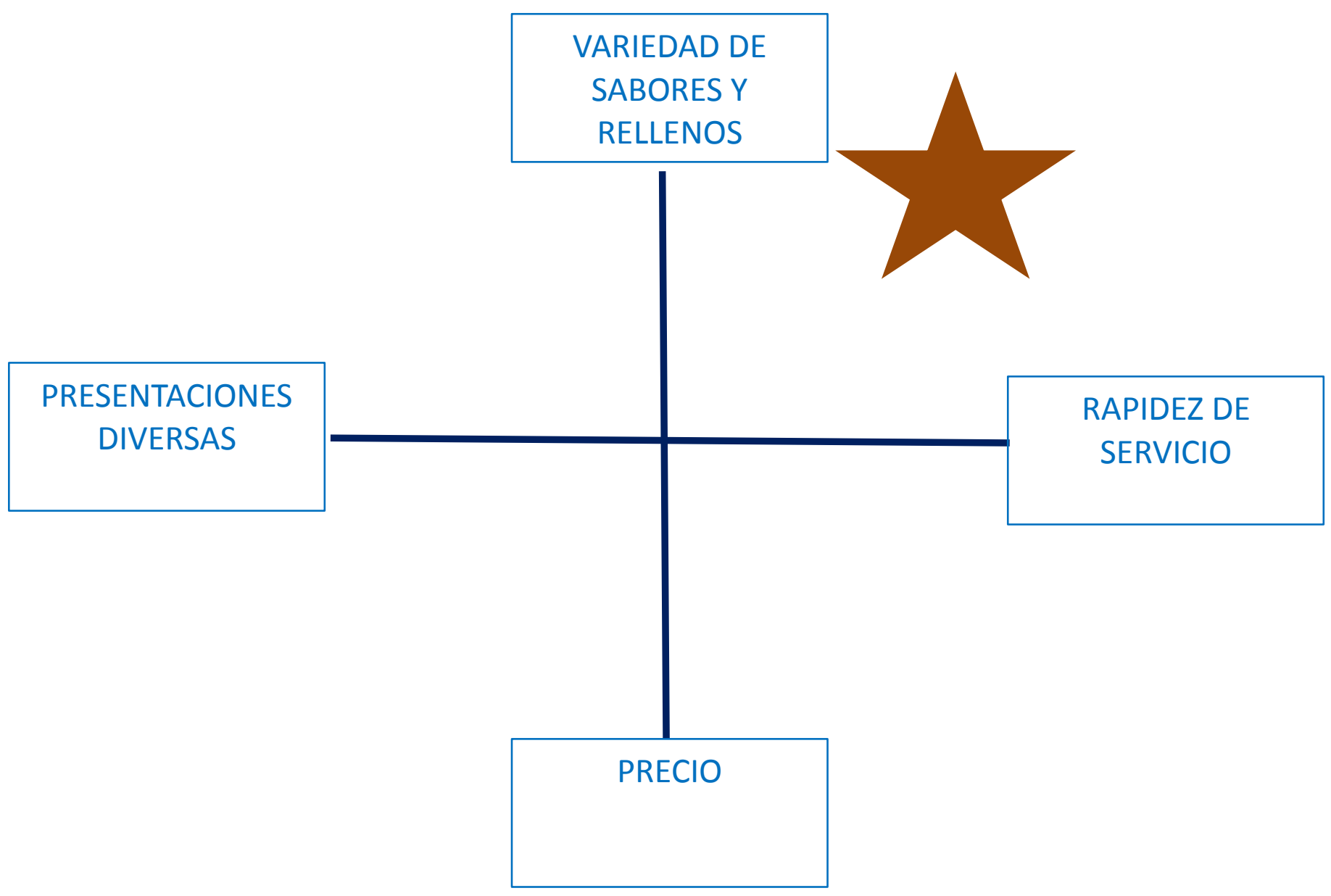

Elaboración propia.

\subsection{Mercado objetivo}

\subsubsection{Tendencia de mercado}

- Mega tendencia de nuevos sabores y colores en la comida.

- Tendencia de consumo de producto nacional.

- Mega tendencia de comida peruana y fusión reconocida como la mejor gastronomía del mundo.

- Tiempo limitado en la vida cotidiana de las personas. 


\subsubsection{Tamaño de mercado}

- Población de Miraflores, San Isidro, San Borja, Surco, La Molina.: 795 mil habitantes.

- Nivel socio económico
○ A (35.9\% de la población)
○ B (43.3\% de la población)
○ C (14.9\% de la población.)

- Población
○ A: 285,405 habitantes.
○ B: 344,235 habitantes.
○ C: 118,455 habitantes.
o Total: 748,095 habitantes.

\subsubsection{Mercado objetivo}

- Todas las personas y miembros de familia de nivel socioeconómico A, B y C que se encuentren entre los 25 y 55 años, que sean económicamente activos, que se consideren early food adopters y con la característica de ser criollo lovers.

\subsubsection{Identificación de agentes}

Figura 4.2

Clientes 


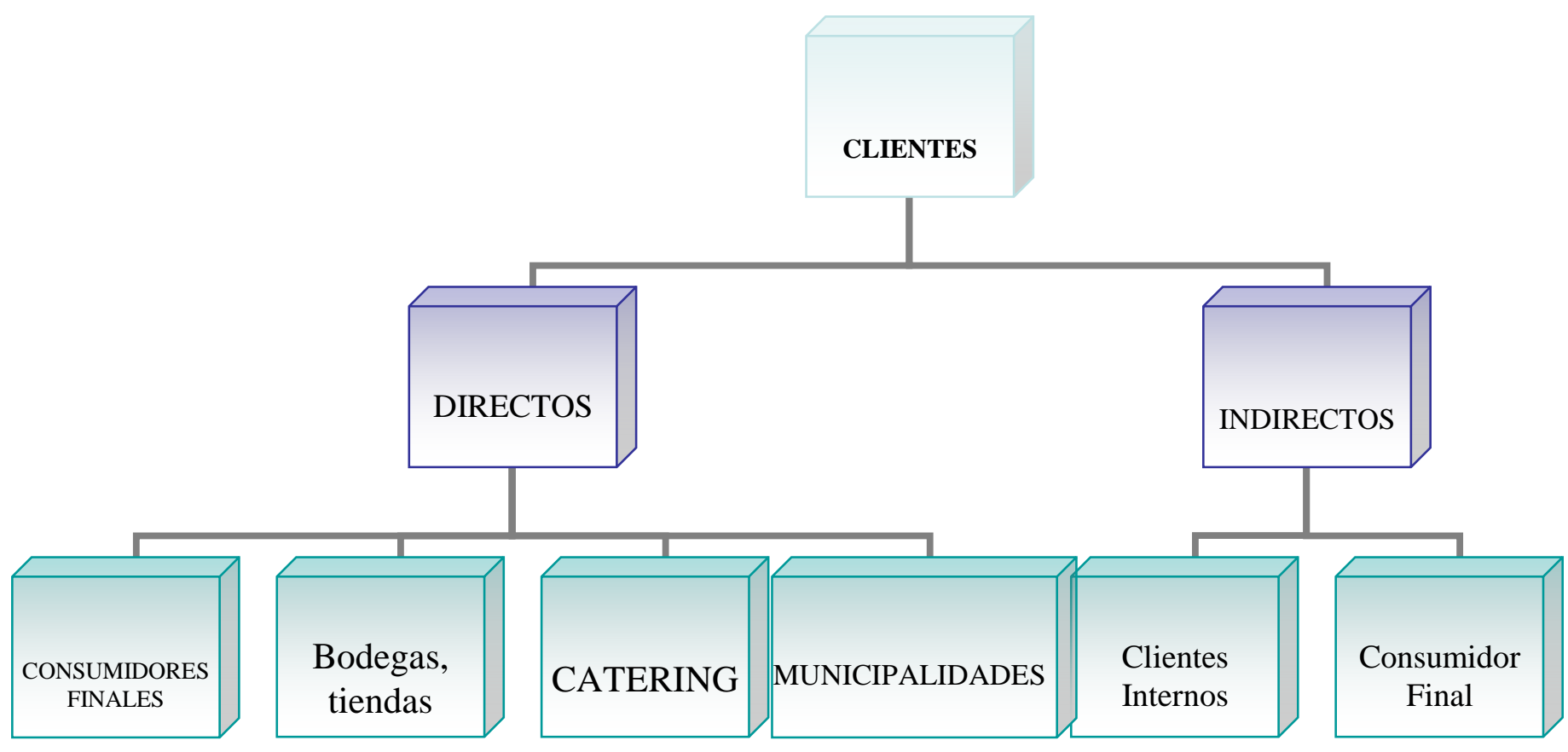

Elaboración propia.

\subsubsection{Potencial de crecimiento del mercado}

- Se estima que la expansión será escalable con una meta de abrir una tienda cada cinco años logrando posicionarnos en los diferentes distritos de la capital en una primera etapa.

\subsubsection{Rivalidad competidora}


Figura 4.3

Competidores

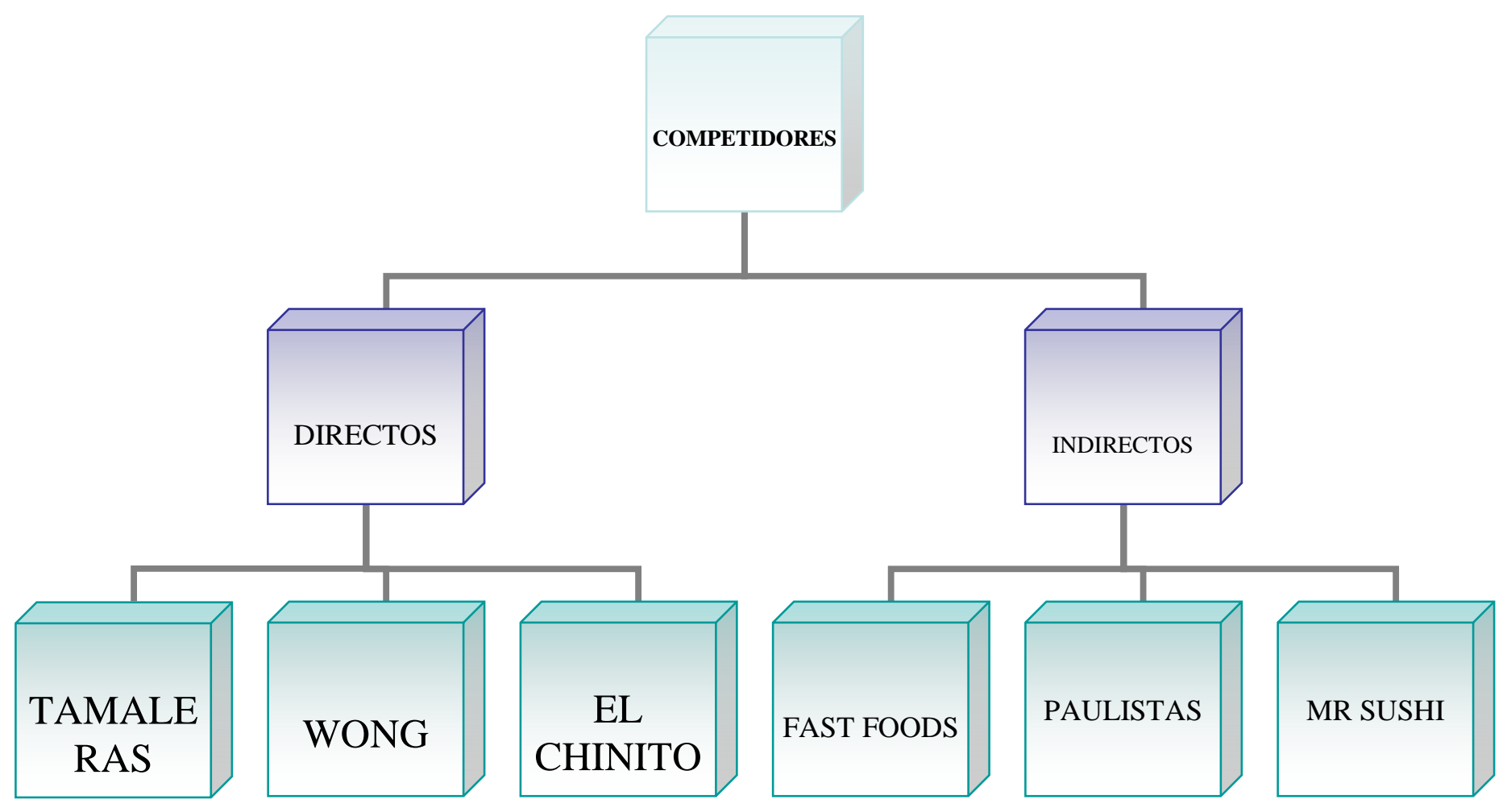

Elaboración propia.

\subsection{Desarrollo y estrategia del marketing mix}

\subsubsection{Política de gestión de clientes}

Nuestra política está orientada a la satisfacción y fidelización del cliente a través del ofrecimiento de una experiencia única (rápida y rica). Para ello, trabajaremos con estándares tanto en nuestro producto como en nuestro servicio. Es este último el principal pilar de nuestro proyecto ya que actualmente nuestros competidores (fast food) no cumplen con los tiempos de espera.

Estamos orientados a superar las expectativas de nuestros clientes, así como también a hacerlos clientes frecuentes a través de iniciativas tales como "crea tu propio relleno en tu cumple" con el fin de lograr un producto a la medida. 
Adicionalmente, consideramos que clientes como caterings también representan potenciales ingresos por lo que también trabajaremos de la mano con ellos a través de la generación de alianzas estratégicas logrando establecer una relación de ganar - ganar.

\subsubsection{Estrategia de producto: especificaciones, calidad, variabilidad $y$ diversificación.}

\subsubsection{Definición de características}

- Peso: 280 gr.

- Masa: maíz tradicional, maíz morado.

- Relleno triturado: pollo, chancho, chancho criollo, cecina con chorizo, lomo saltado.

- Densidad: espesa, contundente.

- Fórmula: 100 gr. de relleno + 180 gr. de masa de maíz.

\subsubsection{Presentación de producto}

- “Tamaléate" tiene una presentación la cual será cilíndrica para reforzar la estrategia de diferenciación.

- Primera presentación: tamal de 280 gr.

\subsubsection{Envase}

- El envase que decidimos utilizar será láminas de papel manteca brandeadas las cuales servirán como envoltura para facilitar la ingesta del producto, adicional a esto ira en una bandeja de cartón brandeada.

\subsubsection{Marca}


- La marca del producto es "Tamaléate" la cual fue ideada por los socios; se llegó a este nombre después de una tormenta de ideas donde se buscaba generar una conexión entre la palabra tamal con alguna expresión coloquial.

\subsubsection{Estrategia de precio}

\subsubsection{Objetivos perseguidos con el Precio Fijado}

- Cubrir los costos totales medios.

- Pronta recuperación de la inversión.

- Empezar a dar un margen considerable de utilidad.

- Rápida acogida del producto.

- Satisfacción total de los consumidores por parte del precio.

- Obtener una rentabilidad prefijada de nuestra inversión.

- Determinar un buen precio meta que esté de acuerdo con la capacidad de producción de la empresa.

\subsubsection{Estrategia de precio}

- Fijar un precio promedio del mercado, con la salvedad de que nuestros productos ofrecen mayor variedad de sabores.

- Mediante una negociación con el proveedor "Tamales Montjoy" se obtendrá una reducción de 0.20 céntimos de sol por unidad cada año si exceden las 100 mil unidades vendidas. Esta reducción será aplicada al precio de venta, logrando reducir este, año a años, a nuestros consumidores.

\subsubsection{Política comercial}

El Food Cost no debe exceder el $32 \%$, actualmente tamaléate tiene un Food Cost de $27 \%$. 
El incremento de ventas por año será de $15 \%$ tomando en cuenta como referente el crecimiento del sector de restauración anual.

\subsubsection{Estrategia comunicacional y canal}

Nuestros tamales son una innovación de un producto ya existente, una variación en la industria de los tamales.

Como somos una organización que no posee elevados recursos económicos, aplicaremos una publicidad que no requiera tantos recursos: folletos en las distintas bocas de salida, degustaciones en las bocas de salida, redes sociales. Los spots publicitarios en televisión, serán a largo plazo, cuando las utilidades obtenidas nos permitan realizar tales gastos.

Tomando como premisa lo antes expuesto "tamaléate" realizara las siguientes acciones para reforzar el plan de comunicación:

- Se utilizará el Facebook Ads para generar una mayor difusión de la marca y se promocionará publicaciones que más interesé a nuestros seguidores y así poder llegar a otras personas para seguir incrementando nuestro número de seguidores.

- En las páginas de las redes sociales se realizarán 2 post diarios en un periodo de tres meses, posterior a esto a un post diario.

Estas acciones han sido determinadas con el fin de cumplir el objetivo de captar la mayor cantidad de seguidores y fans en Facebook e Instagram.

\subsubsection{Estrategia de distribución}

\subsubsection{Nivel de cobertura}

Nuestro producto está dirigido inicialmente a los distritos de San Isidro, Surco, Miraflores, San Borja y La Molina ubicados en Lima Metropolitana de los sectores socio económicos A, B y C, utilizando el criterio selectivo, según los lugares y clientes respectivos, por lo cual, vamos a lograr posicionar nuestro producto el centro comercial Jockey Plaza. 


\subsubsection{Canal de distribución}

Nuestro tipo de canal de distribución es para consumidores finales, es por eso que

"Tamaléate" está implementando un stand up restaurant con un modelo de venta wrap and go en un lugar accesible en el distrito de Santiago de Surco.

\subsubsection{Fuerza de ventas}

- Se usará el método de impulso de venta desde el punto de venta.

- Se contemplarán como propuestas las promociones de los productos, descuentos, hacer encuestas y sugerencias. 


\section{CAPÍTULO V: POLÍTICAS OPERACIONALES}

\subsection{Calidad}

“Tamaléate" procederá a llevar controles de BPM donde se tomarán en cuenta los siguientes factores a evaluar para certificar la calidad e inocuidad del producto.

- Auditoría de calidad, con periodicidad quincenal.

- Auditoría de recetas con periodicidad quincenal.

- Auditoría proveedores con periodicidad mensual.

\subsection{Planificación}

“Tamaléate" cada 03 meses se evaluará y reestructurará el plan de banca de acuerdo a la cantidad de transacciones realizadas.

- Cada 06 meses se realizará la evaluación y actualización de las proyecciones de venta de acuerdo a la realidad del negocio.

- Una vez al año los socios se reunirán y determinarán de acuerdo a las proyecciones y comportamiento de venta de las sucursales.

- Una vez al año los socios se reunirán para realizar el cronograma y presupuesto de mantenimiento de las sucursales de "Tamaléate".

\subsection{Inventarios}

“Tamaléate" utilizará la técnica de flujo de mercadería PEPS (primera entrada, primera salida), permitiendo tener una rotación adecuada de los insumos.

- Las sucursales deben tener dos días de stock de emergencia de los productos más representativos.

- Análisis semanal de pedidos para lo cual se utilizarán las proyecciones de venta con mix de ventas y así poder realizar el pedido de mercadería adecuado contemplando un stock de emergencia de 2 días. 


\subsection{Equipos, actividades y procesos}

"Tamaléate" al ser una empresa que se encargará de comercializar el tamal solo contempla dentro de sus procesos la venta de los mismos hacia el consumidor, mas no la producción de estos, por ende no se contempla indicadores como Lead Time ni Takt time, sin embargo está considerado el tiempo de servicio el cual no debe exceder los 5 minutos por cliente, los cuales se detallan a continuación:

1'30"' Toma de orden

2' 30' Rellenado de masa

1'00'” Entrega de pedido

\subsubsection{Diseño y capacidad de instalaciones}

Cada sucursal de "Tamaléate" tendrá un área de 85 metros cuadrados con un aforo de 48 personas de una sola planta.

\subsubsection{Equipos de trabajo y apoyo}

Cada restaurante "Tamaléate" estará equipado con:

- 06 miembros de equipo full time, 05 miembros de equipo part time, 03 supervisores de tienda y 02 miembros de plana mayor.

- 04 juegos ollas de barro (decorativas).

- 02 mesas de fríos de 3 cuerpos.

- 04 microondas especializados.

- 01 caja registradora.

- 01 refresquera de dos tinas.

- 01 cafetera profesional.

- Small wares.

- 04 maquinas inyectoras.

- 05 termo dispensadores de bebidas calientes.

- Muebles y estructuras. 


\subsubsection{Gestión de proveedores, compras y stock}

Figura 5.1

Proveedores

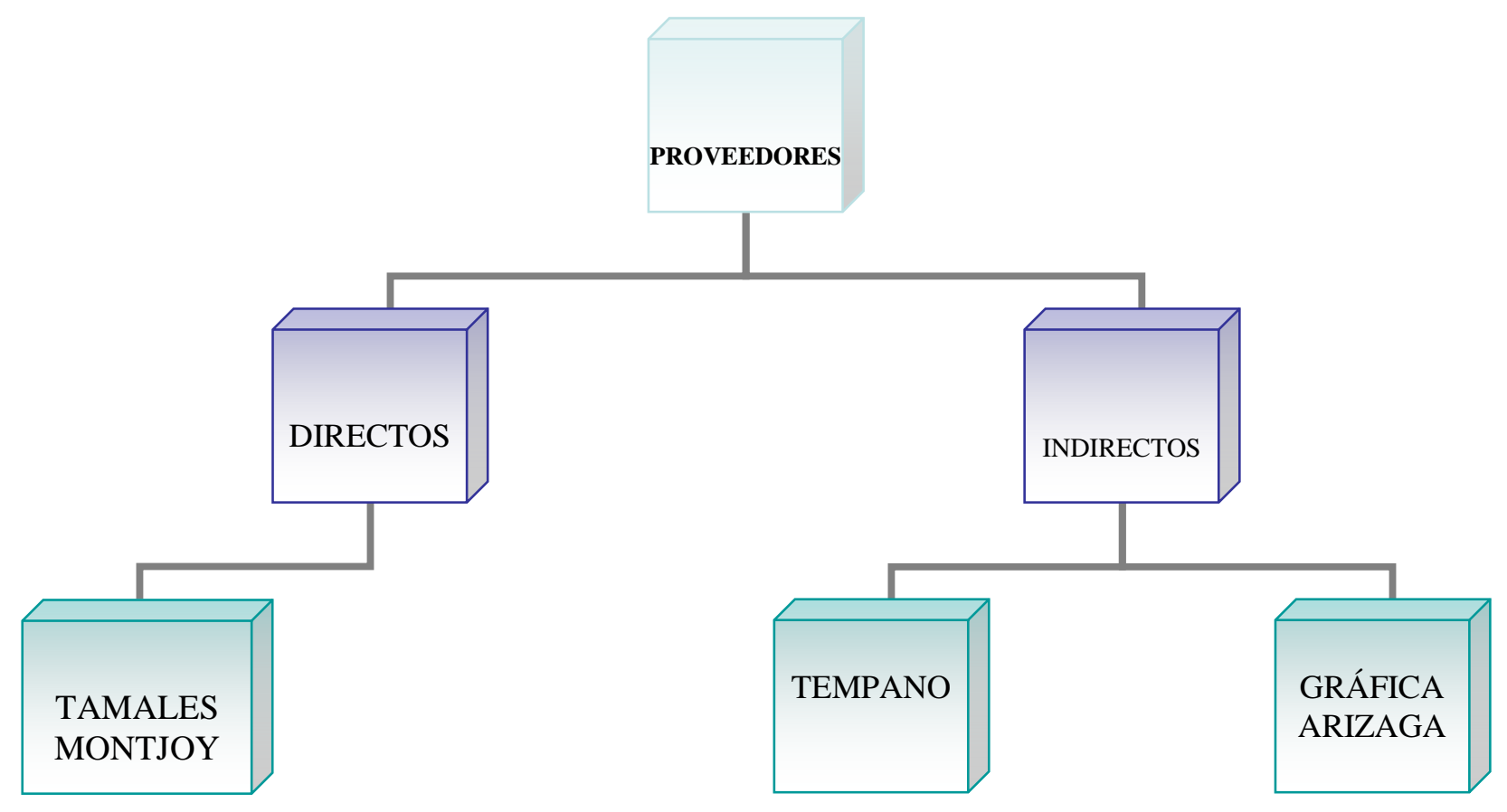

Elaboración propia.

Los pagos se realizarán en un plazo de 30 días, política de cobranza de "Tamales Montjoy”, mientras que "Tempano" y gráfica “Arizaga” los pagos se realizarán a 21 días.

\subsubsection{Tercerización o integración de procesos}

“Tamales Monjoy" es la empresa procesadora de alimentos encargada de realizar los tamales con la receta única de Tamaléate, cabe resaltar que hay un acuerdo de confidencialidad y exclusividad de uso de recetas únicamente para la unidad de negocio "Tamaléate".

"Tamaléate" se encargará de la venta y comercialización de tamales y de la creación de nuevas recetas. 
Figura 5.2

Cadena de valor

\begin{tabular}{|c|c|c|c|c|}
\hline \multicolumn{5}{|c|}{$\begin{array}{l}\text { Reclutamiento, Contratación, Capacitación, Clima laboral, } \\
\text { Línea de carrera }\end{array}$} \\
\hline Creación & \multicolumn{3}{|c|}{$\begin{array}{c}\text { de nuevas recetas, implementación de nuevas } \\
\text { presentaciones }\end{array}$} & \\
\hline $\begin{array}{l}\text { Almacena } \\
\text { miento de } \\
\text { productos } \\
\text { con un día } \\
\text { de stock de } \\
\text { emergencia }\end{array}$ & $\begin{array}{l}\text { Comprar tamales } \\
\text { Ensamblar } \\
\text { pedido. } \\
\text { Verificar pedido } \\
\text { Entregar pedido } \\
\text { Cobrar pedido }\end{array}$ & $\begin{array}{l}\text { Puntos de } \\
\text { venta en } \\
\text { distintas } \\
\text { zonas } \\
\text { geográficas } \\
\text { de Lima }\end{array}$ & $\begin{array}{l}\text { Redes } \\
\text { sociales } \\
\text { Degustacio } \\
\text { nes en } \\
\text { puntos de } \\
\text { venta } \\
\text { folletaje }\end{array}$ & $\begin{array}{l}\text { Encu } \\
\text { salida }\end{array}$ \\
\hline
\end{tabular}

Elaboración propia. 
Figura 5.3

Flujograma de la actividad

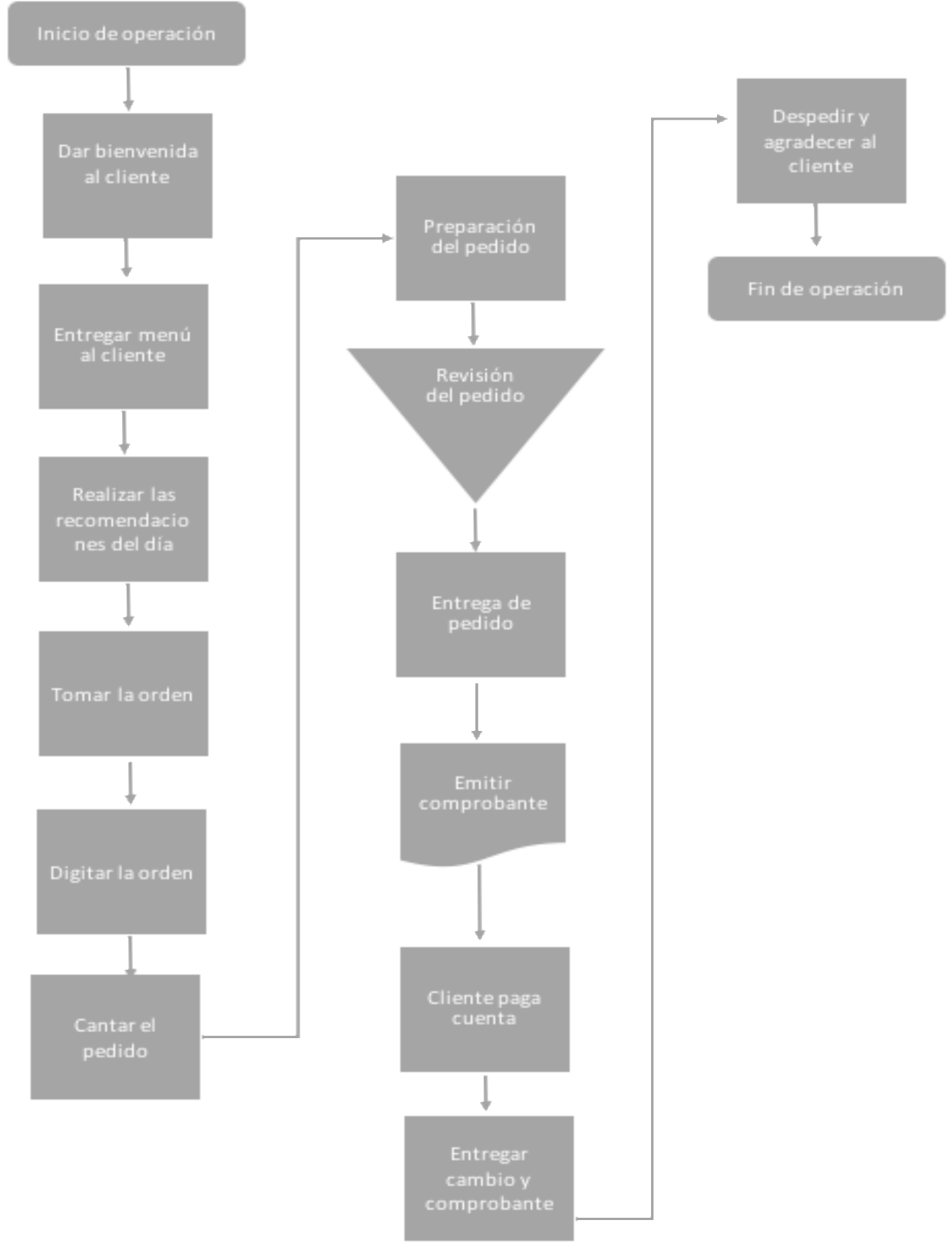

Elaboración propia. 


\section{Figura 5.4}

\section{Balanced Score Card}

\begin{tabular}{|c|c|c|c|}
\hline & Objectivo Estratégicos & Indicadores & Fórmula \\
\hline \multirow{2}{*}{ 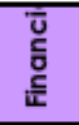 } & Maximizar la rentabilldad de la empresa & Ratio de rentabllidad economica & Utilladad antes impuestos / Activo Total \\
\hline & Generación de ingresos & incremento de ventas & Nentas del ano $x$-ventas der ano $x-1\}-1$ \\
\hline \multirow{6}{*}{$\frac{\text { 은 }}{\frac{\text { 은 }}{2}}$} & Ser considerodo íder & z participación del mercado de tamaies & CMentes nuestros / Cllentes torales del sector \\
\hline & Fildelizar clientes & To de fidellatad del clente & $\begin{array}{l}\text { CNentes que repiren experiencia tamaleate / Toral de clentes que } \\
\text { plden la experiencifa tamaleate }\end{array}$ \\
\hline & Ootención de nuevos cllentes & Múmero de clientes nuevos & Numero de clentes del ano $x /$ Número de clientes del ano $x-1$ \\
\hline & Mejorcr el servicio post--venta & Grado de colldod de ía experiencia & $\begin{array}{l}\text { Sanistacción del clente con atención reguilar / satistacción del } \\
\text { cllente con atención post-venta }\end{array}$ \\
\hline & Estabiecer allanzas estratégicas con proveedores & Cantidad de allanzas estrategias establecidas & Ne allanzas estratéglcas en el ano $x / \mathbb{N}^{*}$ de allanzas en el ano $x-1$ \\
\hline & Garantizar suministro de insumos & F de falla de proweedares & Cantidad de insumos entregados fuera de tiempo / total de insumos \\
\hline \multirow{4}{*}{ 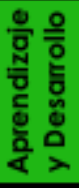 } & Mejorcr el clima labordi & Grado de satisfacción del empleado & Ne de respuestas posilivas $/ N^{p}$ de respuestas totales \\
\hline & $\begin{array}{l}\text { Dor capacltación alineada can objettivos funclonales } \\
\text { y personales }\end{array}$ & Costo meclio de capacitación & 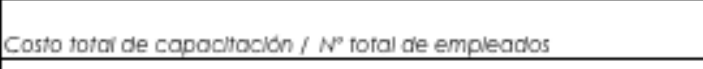 \\
\hline & Desarallar hablidades funcionales & Mumero de capaciraciones especilicas & No de capacitaciones funcionales / $N^{r}$ de capacifiaciones totales \\
\hline & Desarallar competenclas & Evaluaciones de desempeno & Evaluación \\
\hline
\end{tabular}

Elaboración propia. 


\section{CAPÍTULO VI: ESTRUCTURA ORGANIZACIONAL Y RECURSOS HUMANOS}

\subsection{Objetivos organizacionales}

\subsubsection{Naturaleza de la organización}

"Tamaléate" nace con el fin de darle valor a uno de nuestros snacks más consumidos en los hogares peruanos, así como también de satisfacer a un target que está siempre en búsqueda de nuevas experiencias gastronómicas. Nuestras fusiones exquisitas harán que los consumidores tengan mayores posibilidades de elección y, por supuesto, elijan a "Tamaléate" como principal opción de fast food.

\subsubsection{Organigrama}

Nuestra organización estará estructurada de la siguiente manera:

- Gerencia general

- Gerencia comercial

- Supervisores (03)

- $\operatorname{Staff}(11)$

Nota: la contabilidad será llevada, en un inicio, de manera externa por un familiar directo y con ellos nos ahorraremos el costo de este servicio. 
Figura 6.1

Organigrama

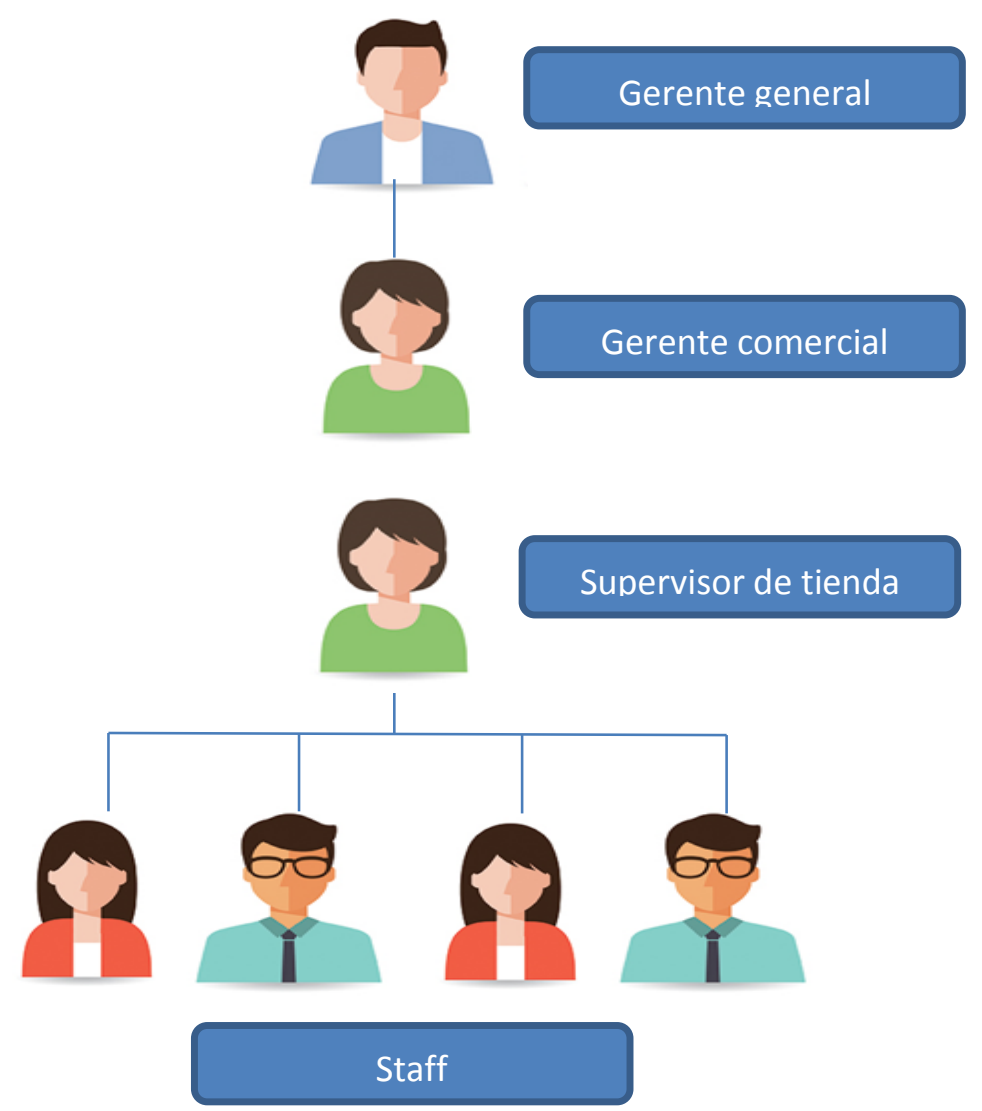

Elaboración propia.

\subsubsection{Diseño estructural por proyectos}

El crecimiento de "Tamaléate" será orgánico. Se tiene proyectado crecer cada tres años con un restaurante. Sin embargo, esta estructura se verá afectada de acuerdo a la demanda.

\subsection{Diseño de puestos y responsabilidades}

- Gerente general: representante legal, responsable de la planificación estratégica, toma de decisiones y promoción de la empresa.

- Gerente comercial: representante legal de la empresa, responsable de las ventas y manejo de personal. 
- Supervisor de tienda: planifica, contrala y ejecuta las operaciones. Vela por el correcto cumplimiento de los estándares.

- Staff: responsables de apertura y/o cierre de local, cuadre de caja, atención de pedidos en mostrador.

\subsection{Políticas organizacionales}

- Contamos con una sola política que se define de la siguiente manera:

○ Tolerancia “ 0 ”, es decir cero:

- Impuntualidad

- Deshonestidad

- Bullying

- Discriminación

- Clientes mal atendidos

- Accidentes

- Aburrimiento

\subsection{Gestión del talento}

\subsubsection{Selección y contratación}

Estos procesos serán realizados por la gerente comercial con la ayuda de una amiga que trabaja en TH (Talento Humano). Para la búsqueda nos apoyaremos en referidos, así como también en plataformas de bolsas de trabajo (Aptitus, Bumeran, entre otras).

\subsubsection{Remuneración y desempeño}

La estructura salarial estará compuesta de un haber básico para el gerente general y gerente comercial. Para el caso del staff, la estructura la componen el haber básico y variable. La parte variable dependerá del cumplimiento, los indicadores de desempeño que serán medidos de manera mensual, siendo la venta y el nivel de satisfacción del 
cliente los principales (este último será medido a través de nuestras encuestas tanto a través de redes sociales como también de manera presencial).

Gerente general: S/. 2000.00

Gerente comercial: S/. 2000.00

Supervisor de tienda: S/. 2000.00

Staff: full time S/.850.00 - part time S/.450.00

\subsubsection{Empowerment y reconocimiento}

Tener a nuestros colaboradores empoderados, con sentido de pertenencia y responsables por las funciones que se les asignen hará que nuestro negocio fluya de manera natural. Para lograr lo antes mencionado se capacitará a nuestro staff con técnicas de venta y buenas prácticas de atención al cliente (nuestros principales indicadores de medición).

En cuanto al reconocimiento, con el fin de motivar al staff contaremos con las siguientes acciones:

- Colaborador del mes: reconocimiento al más destacado, se le identificará con la obtención de un pin. Cada pin acumulado tendrá una puntuación y de llegar a acumular 7 pines, este será premiado con un bono de S/. 100.00.

- Concursos internos: la idea aquí será que se vendan más combos y quien haya vendido la mayor cantidad cada 15 días, tendrá entradas dobles al cine o el pago del almuerzo de un día.

\subsubsection{Capacitación, motivación y desarrollo}

Capacitación:

- Técnicas en el proceso de ventas.

- Atención al cliente.

- Inteligencia emocional.

Motivación y desarrollo:

- Tal y como se ha mencionado en el punto 6.4.3.: 
- Colaborador del mes: reconocimiento al más destacado, se le identificará con la obtención de un pin. Cada pin acumulado tendrá una puntuación y de llegar a acumular 7 pines, este será premiado con un bono de S/. 100.00

- Concursos internos: la idea aquí será que se vendan más combos y quien haya vendido la mayor cantidad cada 15 días, tendrá entradas dobles al cine o el pago del almuerzo de un día.

- En cuanto al desarrollo, este se dará conforme la organización vaya crecimiento. Nuestro objetivo es retener a nuestro staff y poder brindarles línea de carrera; el puesto próximo a requerirse será el de supervisor por lo que visualizamos promocionar al colaborador que obtener el mejor desempeño.

\subsection{Estructura de gastos de RRHH}

Tabla 6.1

Estructura de gastos

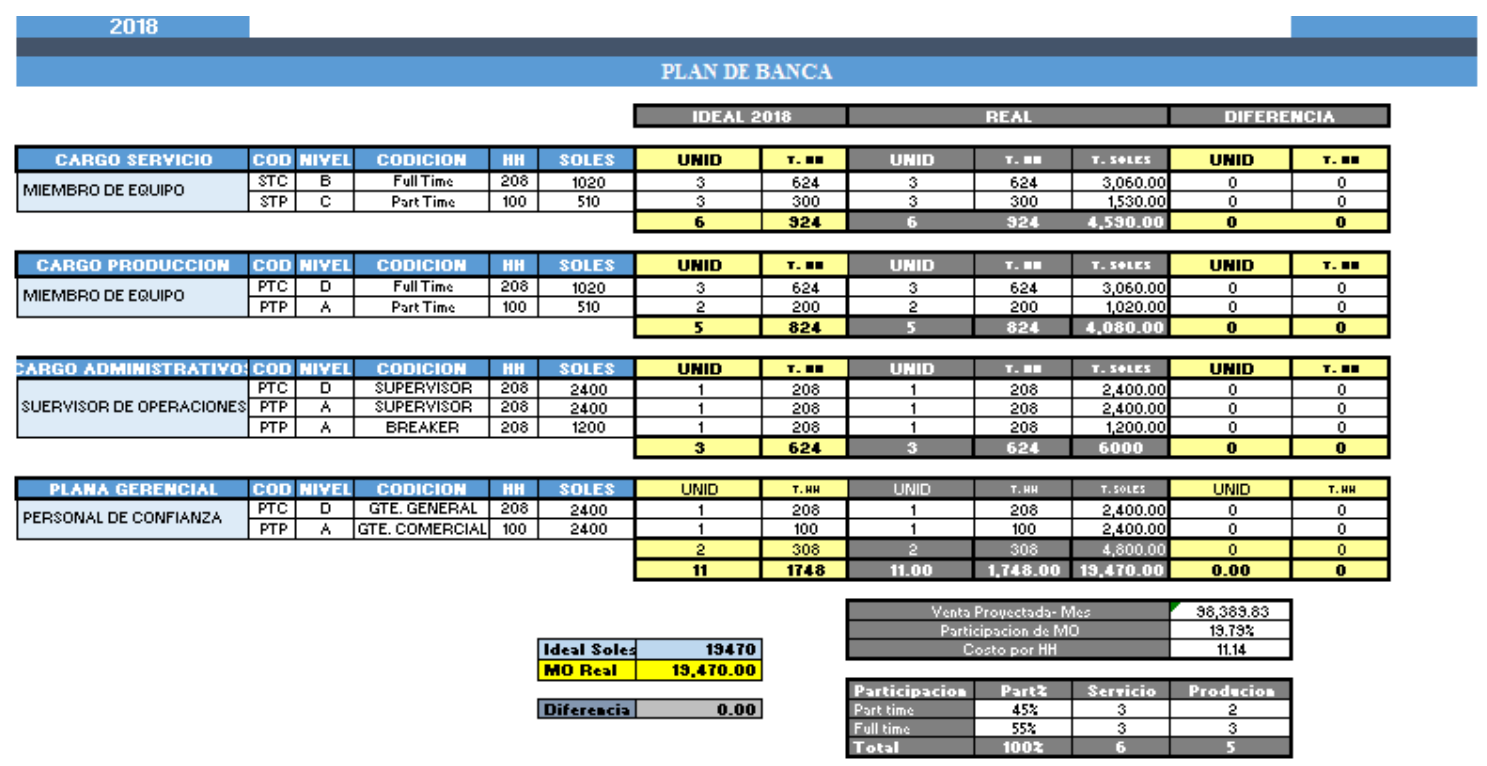

Elaboración propia. 


\section{CAPÍTULO VII: PLAN ECONÓMICO - FINANCIERO}

\subsection{Plan de inversiones}

Tabla 7.1

Estructura de inversión

Estructura de Inversiones (Costo del Proyecto)

(Expresado en Soles y en \%)

\begin{tabular}{|c|c|c|}
\hline Concepto & \multicolumn{1}{|c|}{ Inversión } & Peso \\
\hline Capital de Trabajo & $\mathrm{S} / .75,566.89$ & $25 \%$ \\
\hline Activo Fijo & $\mathrm{S} / .219,016.95$ & $73 \%$ \\
\hline Activo Intangible & $\mathrm{S} / . \quad 4,990.00$ & $2 \%$ \\
\hline Total & $\mathrm{S} / .299,573.84$ & $100 \%$ \\
\hline
\end{tabular}

Elaboración propia.

Tabla 7.2

Estructura de deuda

Estructura de Deuda/Patrimonio (Financiamiento)

(Expresado en Soles y en \%)

\begin{tabular}{|c|c|c|}
\hline Concepto & Inversión & Peso \\
\hline Capital de Trabajo (E) & S/. 59,914.77 & $20 \%$ \\
\hline Pasivo (D) & S/. 239,659.07 & $80 \%$ \\
\hline Total & S/. 299,573.84 & $100 \%$ \\
\hline
\end{tabular}

Elaboración propia. 


\subsection{Activos y depreciación}

Tabla 7.3

Depreciación

Depreciacion de Activos Fijos

(Expresado en Soles)

\begin{tabular}{|c|c|c|c|}
\hline Nombre & Valor Total & Vida Util & Depreciación Anual \\
\hline MESA DE FRIOS & $34,745.76$ & 5 & $6,949.15$ \\
\hline CAJA REGISTRADORA & $1,508.47$ & 5 & 301.69 \\
\hline MAQUINA INYECTORA & $33,559.32$ & 5 & $6,711.86$ \\
\hline THERMO DISPENSADOR DE BEBIDAS CALIENTES & $4,661.02$ & 5 & 932.20 \\
\hline ESTRUCTURA & $135,593.22$ & 5 & $27,118.64$ \\
\hline UTENSILIOS & $5,559.32$ & 5 & $1,111.86$ \\
\hline Total & $215,627.12$ & & $42,013.56$ \\
\hline
\end{tabular}

Elaboración propia.

Tabla 7.4

Amortización

Amortización de Activos Intangibles

(Expresado en Soles)

\begin{tabular}{|l|lr|rr|rr|}
\hline \multicolumn{1}{|c|}{ Nombre } & \multicolumn{2}{c|}{ Valor Total } & \multicolumn{2}{c|}{ Vida Util } & \multicolumn{2}{c|}{ Amortización Anual } \\
\hline DISEÑO DE EMPAQUE & $\mathrm{S} /$. & 550.00 & 5 & $\mathrm{~S} /$. & 110.00 \\
\hline LOGO CORPORATIVO & $\mathrm{S} /$. & 120.00 & 5 & $\mathrm{~S} /$. & 24.00 \\
\hline DESARROLLO DE PAGINA WEB & $\mathrm{S} /$. & $2,520.00$ & 5 & $\mathrm{~S} /$. & 504.00 \\
\hline LICENCIAS & $\mathrm{S} /$. & $1,800.00$ & 5 & $\mathrm{~S} /$. & 360.00 \\
\hline \multicolumn{1}{|c|}{ Total } & $\mathrm{S} /$. & $\mathbf{4 , 9 9 0 . 0 0}$ & & $\mathrm{S} /$. & $\mathbf{9 9 8 . 0 0}$ \\
\hline
\end{tabular}

Elaboración propia. 


\subsection{Capital de trabajo}

Tabla 7.5

Capital de trabajo

\begin{tabular}{|l|lr|}
\hline \multicolumn{1}{|c|}{ CAPITAL DE TRABAJO } & \multicolumn{2}{c|}{} \\
\hline Ingresos & \multicolumn{2}{c|}{ Enero } \\
\hline Costo de Ventas & $\mathrm{S} /$ & 9,153 \\
\hline Suministros & $\mathrm{S} /$. & 12,511 \\
\hline Planilla & $\mathrm{S} /$ & 19,470 \\
\hline Alquiler & $\mathrm{S} /$ & 33,333 \\
\hline Gastos de Ventas & $\mathrm{S} /$ & 1,100 \\
\hline Pago a cuenta del IR (1.5\%) & $\mathrm{S} /$. & - \\
\hline \multicolumn{1}{|c|}{ Flujo de Caja } & $\mathrm{S} /$ & $-75,566.89$ \\
\hline
\end{tabular}

Elaboración propia.

\subsection{Fuentes de financiamiento y amortización}

Tabla 7.6

Condiciones de deuda

\section{Condiciones de la Deuda}

\begin{tabular}{|c|c|}
\hline Banco & $\mathrm{BCP}$ \\
\hline Tasa Anual & $16.0 \%$ \\
\hline Tasa Mensual & $1.24 \%$ \\
\hline Plazo (meses) & 48 \\
\hline Cuota Mensual & S/. $\quad 6,661.90$ \\
\hline
\end{tabular}

Elaboración propia. 
Tabla 7.7

Cronograma de pagos

\begin{tabular}{|c|c|c|c|c|}
\hline \multicolumn{2}{|c|}{ Cronograma de Pagos } & \multirow[b]{2}{*}{ Interes } & \multirow[b]{2}{*}{ Cuota } & \multirow[b]{2}{*}{ Amortizacion } \\
\hline Nro Cuota & Capital & & & \\
\hline 1 & $239,659.07$ & $2,982.59$ & S/. 6,661.90 & $3,679.31$ \\
\hline 2 & $235,979.76$ & $2,936.80$ & S/. 6,661.90 & $3,725.10$ \\
\hline 3 & $232,254.67$ & $2,890.44$ & S/. 6,661.90 & $3,771.45$ \\
\hline 4 & $228,483.21$ & $2,843.51$ & S/. 6,661.90 & $3,818.39$ \\
\hline 5 & $224,664.82$ & $2,795.98$ & S/. 6,661.90 & $3,865.91$ \\
\hline 6 & $220,798.91$ & $2,747.87$ & S/. 6,661.90 & $3,914.02$ \\
\hline 7 & $216,884.89$ & $2,699.16$ & S/. 6,661.90 & $3,962.73$ \\
\hline 8 & $212,922.15$ & $2,649.85$ & S/. 6,661.90 & $4,012.05$ \\
\hline 9 & $208,910.10$ & $2,599.92$ & S/. 6,661.90 & $4,061.98$ \\
\hline 10 & $204,848.12$ & $2,549.36$ & S/. 6,661.90 & $4,112.53$ \\
\hline 11 & $200,735.59$ & $2,498.18$ & S/. 6,661.90 & $4,163.71$ \\
\hline 12 & $196,571.88$ & $2,446.36$ & S/. 6,661.90 & $4,215.53$ \\
\hline 13 & $192,356.34$ & $2,393.90$ & S/. 6,661.90 & $4,267.99$ \\
\hline 14 & $188,088.35$ & $2,340.79$ & S/. 6,661.90 & $4,321.11$ \\
\hline 15 & $183,767.24$ & $2,287.01$ & S/. 6,661.90 & $4,374.89$ \\
\hline 16 & $179,392.35$ & $2,232.56$ & S/. 6,661.90 & $4,429.33$ \\
\hline 17 & $174,963.02$ & $2,177.44$ & S/. 6,661.90 & $4,484.46$ \\
\hline 18 & $170,478.56$ & $2,121.63$ & S/. $6,661.90$ & $4,540.27$ \\
\hline 19 & $165,938.29$ & $2,065.12$ & S/. 6,661.90 & $4,596.77$ \\
\hline 20 & $161,341.52$ & $2,007.92$ & S/. $6,661.90$ & $4,653.98$ \\
\hline 21 & $156,687.54$ & $1,950.00$ & S/. 6,661.90 & $4,711.90$ \\
\hline 22 & $151,975.65$ & $1,891.36$ & S/. 6,661.90 & $4,770.54$ \\
\hline 23 & $147,205.11$ & $1,831.99$ & S/. 6,661.90 & $4,829.91$ \\
\hline 24 & $142,375.20$ & $1,771.88$ & S/. $6,661.90$ & $4,890.02$ \\
\hline 25 & $137,485.18$ & $1,711.02$ & S/. 6,661.90 & $4,950.87$ \\
\hline 26 & $132,534.31$ & $1,649.41$ & S/. $6,661.90$ & $5,012.49$ \\
\hline 27 & $127,521.82$ & $1,587.03$ & S/. 6,661.90 & $5,074.87$ \\
\hline 28 & $122,446.95$ & $1,523.87$ & S/. $6,661.90$ & $5,138.03$ \\
\hline 29 & $117,308.92$ & $1,459.93$ & S/. 6,661.90 & $5,201.97$ \\
\hline 30 & $112,106.95$ & $1,395.19$ & S/. 6,661.90 & $5,266.71$ \\
\hline 31 & $106,840.24$ & $1,329.64$ & S/. 6,661.90 & $5,332.25$ \\
\hline 32 & $101,507.99$ & $1,263.28$ & S/. 6,661.90 & $5,398.62$ \\
\hline 33 & $96,109.37$ & $1,196.09$ & S/. 6,661.90 & $5,465.80$ \\
\hline 34 & $90,643.57$ & $1,128.07$ & S/. $6,661.90$ & $5,533.82$ \\
\hline 35 & $85,109.75$ & $1,059.20$ & S/. 6,661.90 & $5,602.69$ \\
\hline 36 & $79,507.05$ & 989.48 & S/. 6,661.90 & $5,672.42$ \\
\hline 37 & $73,834.64$ & 918.88 & S/. 6,661.90 & $5,743.01$ \\
\hline 38 & $68,091.62$ & 847.41 & S/. 6,661.90 & $5,814.49$ \\
\hline 39 & $62,277.13$ & 775.05 & S/. 6,661.90 & $5,886.85$ \\
\hline 40 & $56,390.29$ & 701.78 & S/. 6,661.90 & $5,960.11$ \\
\hline 41 & $50,430.18$ & 627.61 & S/. 6,661.90 & $6,034.29$ \\
\hline 42 & $44,395.89$ & 552.51 & S/. 6,661.90 & $6,109.38$ \\
\hline 43 & $38,286.51$ & 476.48 & S/. 6,661.90 & $6,185.42$ \\
\hline 44 & $32,101.09$ & 399.50 & S/. 6,661.90 & $6,262.39$ \\
\hline 45 & $25,838.70$ & 321.57 & S/. $6,661.90$ & $6,340.33$ \\
\hline 46 & $19,498.37$ & 242.66 & S/. 6,661.90 & $6,419.24$ \\
\hline 47 & $13,079.13$ & 162.77 & S/. $6,661.90$ & $6,499.12$ \\
\hline 48 & $6,580.01$ & 81.89 & S/. 6,661.90 & $6,580.01$ \\
\hline
\end{tabular}

Elaboración propia. 


\subsection{Balances previsionales (Balance general)}

Tabla 7.8

Balance proyectado

\begin{tabular}{|c|c|c|c|c|c|}
\hline & 2018 & 2019 & 2020 & 2021 & 2022 \\
\hline Activo Total & 402,103 & 432,241 & 499,829 & 650,203 & 972,034 \\
\hline Activo Corriente & 223,500 & 253,637 & 321,226 & 471,600 & 793,430 \\
\hline Caja y banco & 75,567 & 253,637 & 231,300 & 323,460 & 422,014 \\
\hline Existencias & 147,933 & & 89,926 & 148,140 & 371,416 \\
\hline Activo no Corriente & 178,604 & 178,604 & 178,604 & 178,604 & 178,604 \\
\hline Maquinarias y equipos & 215,627 & 215,627 & 215,627 & 215,627 & 215,627 \\
\hline Depreciación & $-42,014$ & $-42,014$ & $-42,014$ & $-42,014$ & $-42,014$ \\
\hline Intangibles & 4,990 & 4,990 & 4,990 & 4,990 & 4,990 \\
\hline Amortizacion & -998 & -998 & -998 & -998 & -998 \\
\hline Pasivo y Patrimonio & 402,103 & 422,136 & 501,143 & 640,937 & 958,403 \\
\hline Pasivo Total & 88,552 & 130,922 & 117,768 & 159,007 & 230,368 \\
\hline Pasivo Corriente & 88,552 & 130,922 & 117,768 & 159,007 & 230,368 \\
\hline Otras cuentas por pagar & & 51,717 & & & \\
\hline Impuestos por pagar & 88,552 & 79,205 & 117,768 & 159,007 & 230,368 \\
\hline \multicolumn{6}{|c|}{ Pasivo no Corriente (financiero) } \\
\hline Patrimonio Neto & 313,552 & 291,214 & 383,374 & 481,929 & 728,035 \\
\hline Capital Social & 59,915 & 59,915 & 59,915 & 59,915 & 59,915 \\
\hline Utilidad del Ejercicio & 253,637 & 231,300 & 323,460 & 422,014 & 668,121 \\
\hline
\end{tabular}

Elaboración propia. 


\subsection{Cuentas de explotación previsionales (GGPP)}

Tabla 7.9

Estado de Ganancias y Pérdidas

\begin{tabular}{|c|c|c|c|c|c|}
\hline E.G.P & 2018 & 2019 & 2020 & 2021 & 2022 \\
\hline & $\mathrm{S} /$. & S/. & S/. & $\mathrm{S} /$. & S/. \\
\hline Ventas & $1,180,678$ & $1,336,729$ & $1,537,238$ & $1,753,904$ & $2,000,982$ \\
\hline Costo de Ventas & $-497,743$ & $-559,766$ & $-621,531$ & $-689,737$ & $-764,974$ \\
\hline Utilidad Bruta & 682,935 & 776,963 & 915,707 & $1,064,167$ & $1,236,008$ \\
\hline Gastos de Administracion & $-225,977$ & $-245,447$ & $-245,447$ & $-245,447$ & $-245,447$ \\
\hline Gastos de Ventas & $-13,200$ & $-13,200$ & $-13,200$ & $-13,200$ & $-13,200$ \\
\hline Utilidad de Operación & 443,759 & 518,316 & 657,060 & 805,521 & 977,361 \\
\hline Gastos Financieros & $-79,943$ & $-79,943$ & $-79,943$ & $-79,943$ & - \\
\hline Otros Egresos & $-16,414$ & $-116,414$ & $-116,414$ & $-116,414$ & $-116,414$ \\
\hline Utilidad antes de impuestos & 347,402 & 321,960 & 460,704 & 609,164 & 860,947 \\
\hline Impuesto a la renta & $-102,484$ & $-94,978$ & $-135,908$ & $-179,703$ & $-253,979$ \\
\hline Depreciacion & 42,014 & 42,014 & 42,014 & 42,014 & 42,014 \\
\hline Resultado del Ejercicio & $286,932.15$ & $268,995.37$ & $366,809.72$ & $471,474.45$ & $648,981.39$ \\
\hline
\end{tabular}

Elaboración propia.

7.7 Proyección de ventas y Flujo de Tesorería (Cash flow) 
Tabla 7.10

Flujo de caja proyectado

\begin{tabular}{|c|c|c|c|c|c|c|c|c|c|c|c|c|}
\hline \multirow[b]{2}{*}{ INVERSION INICIAL } & \multicolumn{12}{|c|}{ PERIODO DE TIEMPO EXPRESADO EN AÑOS } \\
\hline & \multicolumn{3}{|c|}{0} & 1 & \multicolumn{2}{|r|}{2} & \multicolumn{2}{|c|}{3} & \multicolumn{2}{|r|}{4} & \multicolumn{2}{|r|}{5} \\
\hline EQUIPAMENTO & $\mathrm{S} /$. & $83,423.73$ & & & & & & & & & & \\
\hline ESTRUCTURAS & $\mathrm{S} /$. & $135,593.22$ & & & & & & & & & & \\
\hline INTANGIBLES & $\mathrm{S} /$. & $4,990.00$ & & & & & & & & & & \\
\hline CAPITAL DE TRABAJO & $\mathrm{S} /$. & $75,566.89$ & & & & & & & & & & \\
\hline TOTAL INVERSION & S/. & $299,573.84$ & $\mathrm{~S} /$. & - & $\mathrm{S} /$. & - & $\mathrm{S} /$. & - & S/. & - & $\mathrm{S} /$. & - \\
\hline INGRESOS & & & & 2,018 & & 2,019 & & 2,020 & & 2,021 & & 2,022 \\
\hline VENTAS COMBOS TAMALEATE & & & $\mathrm{S} /$. & $1,180,677.97$ & $\mathrm{~S} /$. & $1,336,728.81$ & $\mathrm{~S} /$. & $1,537,238.14$ & $\mathrm{~S} /$. & $1,753,903.98$ & $\mathrm{~S} /$. & $2,000,981.73$ \\
\hline TOTAL INGRESOS & & & $\mathrm{S} /$. & $1,180,677.97$ & $\mathrm{~S} /$. & $1,336,728.81$ & $\mathrm{~S} /$. & $1,537,238.14$ & $\mathrm{~S} /$. & $1,753,903.98$ & $\mathrm{~S} /$. & $2,000,981.73$ \\
\hline \multicolumn{13}{|l|}{ EGRESOS } \\
\hline \multicolumn{13}{|l|}{ COSTOS } \\
\hline COSTO TAMALES TAMALEATE & & & $\mathrm{S} /$. & $329,491.53$ & $\mathrm{~S} /$. & $357,864.41$ & $\mathrm{~S} /$. & $399,439.83$ & $\mathrm{~S} /$. & $445,435.93$ & $\mathrm{~S} /$. & $496,243.47$ \\
\hline SUMINISTROS & & & $\mathrm{S} /$. & $168,251.09$ & $\mathrm{~S} /$. & $201,901.30$ & $\mathrm{~S} /$. & $222,091.43$ & $\mathrm{~S} /$. & $244,300.58$ & $\mathrm{~S} /$. & $268,730.63$ \\
\hline FIJO ALQUILER & & & $-\mathrm{S} /$. & $25,600.00$ & $\mathrm{~S} /$. & $74,400.00$ & $\mathrm{~S} /$. & $74,400.00$ & $\mathrm{~S} /$. & $74,400.00$ & $\mathrm{~S} /$. & $74,400.00$ \\
\hline TOTAL COSTOS & $\mathrm{S} /$. & - & $\mathrm{S} /$. & $472,142.61$ & $\mathrm{~S} /$. & $634,165.71$ & $\mathrm{~S} /$. & $695,931.26$ & S/. & $764,136.51$ & S/. & $839,374.10$ \\
\hline \multicolumn{13}{|l|}{ GASTOS } \\
\hline RRHH & & & $\mathrm{S} /$. & $214,170.00$ & $\mathrm{~S} /$. & $233,640.00$ & $\mathrm{~S} /$. & $233,640.00$ & $\mathrm{~S} /$. & $233,640.00$ & $\mathrm{~S} /$. & $233,640.00$ \\
\hline $\mathrm{I} \& \mathrm{D}$ & & & $\mathrm{S} /$ & $47,227.12$ & $\mathrm{~S} /$ & $53,469.15$ & $\mathrm{~S} /$. & $61,489.53$ & $\mathrm{~S} /$. & $70,156.16$ & $\mathrm{~S} /$. & $80,039.27$ \\
\hline GASTO DE VENTAS & & & $\mathrm{S} /$. & $13,200.00$ & $\mathrm{~S} /$. & $13,200.00$ & $\mathrm{~S} /$. & $13,200.00$ & $\mathrm{~S} /$. & $13,200.00$ & $\mathrm{~S} /$. & $13,200.00$ \\
\hline GASTO FINANCIERO & & & $\mathrm{S} /$. & $47,302.73$ & $\mathrm{~S} /$. & $54,871.16$ & $\mathrm{~S} /$. & $63,650.55$ & $\mathrm{~S} /$. & $73,834.64$ & & \\
\hline INTERES PAGADO & & & $\mathrm{S} /$. & $32,640.03$ & $\mathrm{~S} /$. & $25,071.59$ & $\mathrm{~S} /$. & $16,292.21$ & $\mathrm{~S} /$. & $6,108.12$ & & \\
\hline OTROS GASTOS & & & $\mathrm{S} /$. & $11,806.78$ & $\mathrm{~S} /$. & $11,806.78$ & $\mathrm{~S} /$. & $11,806.78$ & $\mathrm{~S} /$. & $11,806.78$ & $\mathrm{~S} /$. & $11,806.78$ \\
\hline DEPRECIACION & & & S/. & $42,013.56$ & $\mathrm{~S} /$. & $42,013.56$ & $\mathrm{~S} /$. & $42,013.56$ & $\mathrm{~S} /$. & $42,013.56$ & $\mathrm{~S} /$. & $42,013.56$ \\
\hline TOTAL GASTOS & $\mathrm{S} /$. & - & S/. & $408,360.21$ & $\mathrm{~S} / \mathrm{.}$ & $434,072.24$ & $\mathrm{~S} /$. & $442,092.62$ & S/. & $450,759.25$ & $\mathrm{~S} /$. & $380,699.61$ \\
\hline $\begin{array}{l}\text { TOTAL EGRESOS } \\
\end{array}$ & $\mathrm{S} /$. & - & $\mathrm{S} /$. & $880,502.82$ & $\mathrm{~S} /$. & $1,068,237.95$ & $\mathrm{~S} /$. & $1,138,023.88$ & S/. & $1,214,895.76$ & S/. & $1,220,073.71$ \\
\hline $\begin{array}{l}\text { FLUJO OPERATIVO } \\
\end{array}$ & & & $\mathrm{S} /$. & $300,175.14$ & $\mathrm{~S} /$. & $268,490.86$ & $\mathrm{~S} /$. & $399,214.25$ & $\mathrm{~S} /$. & $539,008.22$ & $\mathrm{~S} /$. & $780,908.02$ \\
\hline IR & & & $-\mathrm{S} /$. & $88,551.67$ & $-S /$. & $79,204.80$ & $-\mathrm{S} /$ & $117,768.20$ & $-\mathrm{S} /$. & $159,007.43$ & $-\mathrm{S} /$ & $230,367.86$ \\
\hline DEPRECIACIÓN & & & S/. & $42,013.56$ & S/. & $42,013.56$ & $\mathrm{~S} /$ & $42,013.56$ & S/. & $42,013.56$ & $\mathrm{~S} /$. & $42,013.56$ \\
\hline INVERSION & $\mathrm{S} /$. & $299,573.84$ & & & & & & & $\mathrm{~S} /$. & - & & \\
\hline CAPITAL DE TRABAJO & & & & & & & & & & & $\mathrm{S} /$. & $75,566.89$ \\
\hline FLUJO DE CAJA FINANCIERO & $-\mathrm{S} /$. & $299,573.84$ & S/. & $253,637.04$ & S/. & $231,299.61$ & $\mathrm{~S} /$. & $323,459.61$ & S/. & $422,014.36$ & $\mathrm{~S} /$. & $668,120.60$ \\
\hline
\end{tabular}

Elaboración propia.

\subsection{Análisis de viabilidad y rentabilidad financiera}


Tabla 7.11

VAN y TIR

\begin{tabular}{|l|r|}
\hline VAN & $731,622.77$ \\
\hline
\end{tabular}

\begin{tabular}{|l|r|}
\hline TIR & $91.30 \%$ \\
\hline
\end{tabular}

Elaboración propia.

\subsection{Indicadores de rentabilidad representativos}

Tabla 7.12

Ratios de liquidez.

\begin{tabular}{|c|c|c|c|c|c|c|c|c|}
\hline RATIOS DE LIQUIDEZ & & 2018 & 2019 & & 2020 & & 2021 & 2022 \\
\hline LIQUIDEZ CORRIENTE o GENERAL & & 2.52 & 1.94 & & 2.73 & & 2.97 & 3.44 \\
\hline ACT DISP - GTOS PAG $\times$ ANTICIPADO & $\mathrm{S} /$. & $223,499.89$ & S/. $253,637.04$ & $\mathrm{~S} /$. & $321,225.61$ & $\mathrm{~S} /$. & $471,599.61$ & $\mathrm{~S} / .793,430.36$ \\
\hline PASIVO CORRIENTE & $\mathrm{S} / \mathrm{.}$ & $88,551.67$ & S/. $130,921.80$ & $\mathrm{~S} / \mathrm{.}$ & $117,768.20$ & $\mathrm{~S} / \mathrm{.}$ & $159,007.43$ & $\mathrm{~S} / 230,367.86$ \\
\hline LIQUIDEZ ACIDA & & 0.85 & 1.94 & & 1.96 & & 2.03 & 1.83 \\
\hline ACT CTE - GTOS PAG $\times$ ANT - EXISTENCIAS & $\mathrm{S} /$ & $75,566.89$ & S/. $253,637.04$ & $\mathrm{~S} /$. & $231,299.61$ & $\mathrm{~S} /$. & $323,459.61$ & S/.422,014.36 \\
\hline PASIVO CORRIENTE & $\mathrm{S} /$. & $88,551.67$ & S/. $130,921.80$ & $\mathrm{~S} /$. & $117,768.20$ & $\mathrm{~S} / \mathrm{.}$ & $159,007.43$ & $\mathrm{~S} / .230,367.86$ \\
\hline LIQUIDEZ SEVERA & & 0.85 & 1.94 & & 1.96 & & 2.03 & 1.83 \\
\hline ACT CTE - GTOS PAG $\times$ ANT - EXISTENCIAS- CTAS $\times$ COB & $\mathrm{S} /$. & $75,566.89$ & S/. $253,637.04$ & $\mathrm{~S} /$. & $231,299.61$ & $\mathrm{~S} /$. & $323,459.61$ & $\mathrm{~S} / 422,014.36$ \\
\hline PASIVO CORRIENTE & $\mathrm{S} /$. & $88,551.67$ & S/. $130,921.80$ & S/. & $117,768.20$ & S/. & $159,007.43$ & $\mathrm{~S} / .230,367.86$ \\
\hline MARGEN DE SEGURIDAD & & 0.85 & 0.00 & & 0.00 & & 0.00 & 0.00 \\
\hline CAPITAL DE TRABAJO. & $\mathrm{S} /$. & $75,566.89$ & $\mathrm{~S} /$. & S/. & - & S/. & . & $\mathrm{S} /$. \\
\hline PASIVO CORRIENTE & $\mathrm{S} /$. & $88,551.67$ & S/. $130,921.80$ & $\mathrm{~S} /$. & $117,768.20$ & $\mathrm{~S} /$. & $159,007.43$ & $\mathrm{~S} / .230,367.86$ \\
\hline
\end{tabular}

Elaboración propia.

Tabla 7.13

Ratios de endeudamiento 


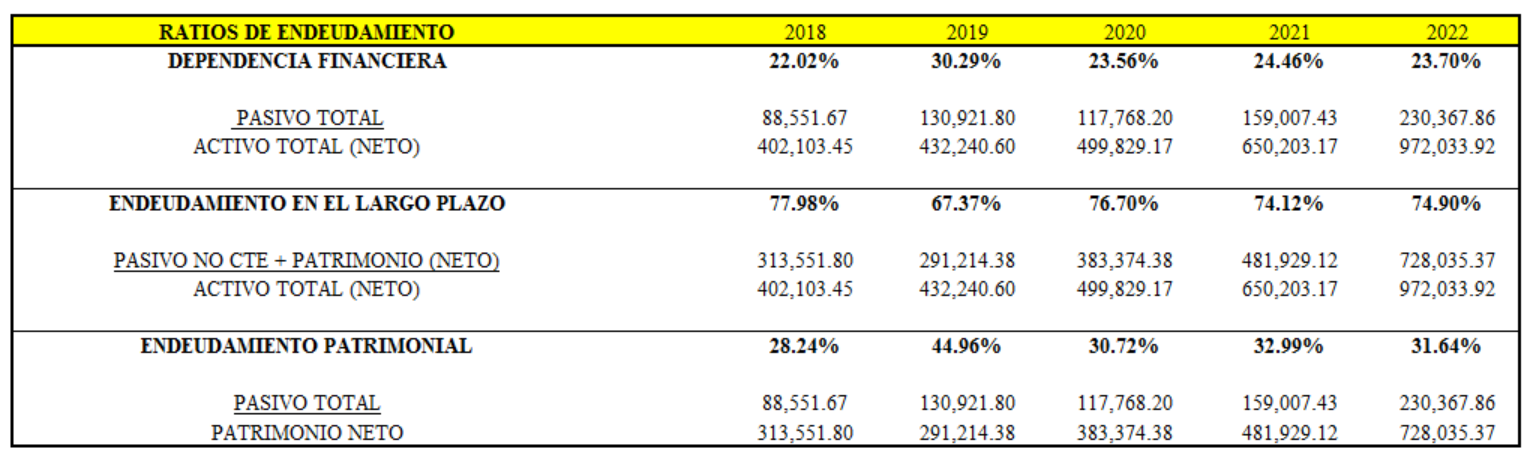

Elaboración propia.

Tabla 7.14

Ratios de rentabilidad. Parte I

\begin{tabular}{|c|c|c|c|c|c|}
\hline RATIOS DE RENTABILIDAD & 2018 & 2019 & 2020 & 2021 & 2022 \\
\hline COSTO DE VENTAS & $42.16 \%$ & $41.88 \%$ & $40.43 \%$ & $39.33 \%$ & $38.23 \%$ \\
\hline COSTO VENTAS & $497,742.61$ & $559,765.71$ & $621,531.26$ & $689,736.51$ & $764,974.10$ \\
\hline VENTAS NETAS & $1,180,677.97$ & $1,336,728.81$ & $1,537,238.14$ & $1,753,903.98$ & $2,000,981.73$ \\
\hline GASTOS FINANCIEROS & $6.77 \%$ & $5.98 \%$ & $5.20 \%$ & $4.56 \%$ & $0.00 \%$ \\
\hline GASTOS FINANCIEROS & $79,942.75$ & $79,942.75$ & $79,942.75$ & $79,942.75$ & 0.00 \\
\hline VENTAS NETAS & $1,180,677.97$ & $1,336,728.81$ & $1,537,238.14$ & $1,753,903.98$ & $2,000,981.73$ \\
\hline COSTOS TOTALES & $48.93 \%$ & $47.86 \%$ & $45.63 \%$ & $43.88 \%$ & $38.23 \%$ \\
\hline COSTO VENTA + GTOS OPERAT + GTOS FINANCIEROS & $577,685.36$ & $639,708.46$ & $701,474.02$ & $769,679.26$ & $764,974.10$ \\
\hline VENTAS NETAS & $1,180,677.97$ & $1,336,728.81$ & $1,537,238.14$ & $1,753,903.98$ & $2,000,981.73$ \\
\hline
\end{tabular}

Elaboración propia.

Tabla 7.15

Ratios de rentabilidad. Parte II 


\begin{tabular}{|c|c|c|c|c|c|}
\hline RATIOS DE RENTABILIDAD & 2018 & 2019 & 2020 & 2021 & 2022 \\
\hline UTILIDAD OPERATIVA/ACTIVO TOTAL (ROA) & $110.36 \%$ & $119.91 \%$ & $131.46 \%$ & $123.89 \%$ & $100.55 \%$ \\
\hline UTILIDAD OPERATIVA & $443,758.57$ & $518,316.32$ & $657,060.09$ & $805,520.69$ & $977,360.84$ \\
\hline ACTIVO TOTAL & $402,103.45$ & $432,240.60$ & $499,829.17$ & $650,203.17$ & $972,033.92$ \\
\hline UTILIDAD NETA / ACTIVO TOTAL (ROA) & $71.36 \%$ & $62.23 \%$ & $73.39 \%$ & $72.51 \%$ & $66.77 \%$ \\
\hline UTILIDAD NETA & $286,932.15$ & $268,995.37$ & $366,809.72$ & $471,474.45$ & $648,981.39$ \\
\hline ACTIVO TOTAL & $402,103.45$ & $432,240.60$ & $499,829.17$ & $650,203.17$ & $972,033.92$ \\
\hline UTILIDAD OPERATIVA/CAPITAL (ROE) & $141.53 \%$ & $177.98 \%$ & $171.39 \%$ & $167.15 \%$ & $134.25 \%$ \\
\hline UTILIDAD OPERATIVA & $443,758.57$ & $518,316.32$ & $657,060.09$ & $805,520.69$ & $977,360.84$ \\
\hline CAPITAL CONTABLE (PATRIMONIO) & $313,551.80$ & $291,214.38$ & $383,374.38$ & $481,929.12$ & $728,035.37$ \\
\hline UTILIDAD NETA / CAPITAL (ROE) & $91.51 \%$ & $92.37 \%$ & $95.68 \%$ & $97.83 \%$ & $89.14 \%$ \\
\hline UTILIDAD NETA & $286,932.15$ & $268,995.37$ & $366,809.72$ & $471,474.45$ & $648,981.39$ \\
\hline CAPITAL CONTABLE (PATRIMONIO) & $313,551.80$ & $291,214.38$ & $383,374.38$ & $481,929.12$ & $728,035.37$ \\
\hline
\end{tabular}

Elaboración propia.

\subsection{Análisis de riesgo y costo de oportunidad}

Tabla 7.16

Análisis de WACC mediante modelo KPM
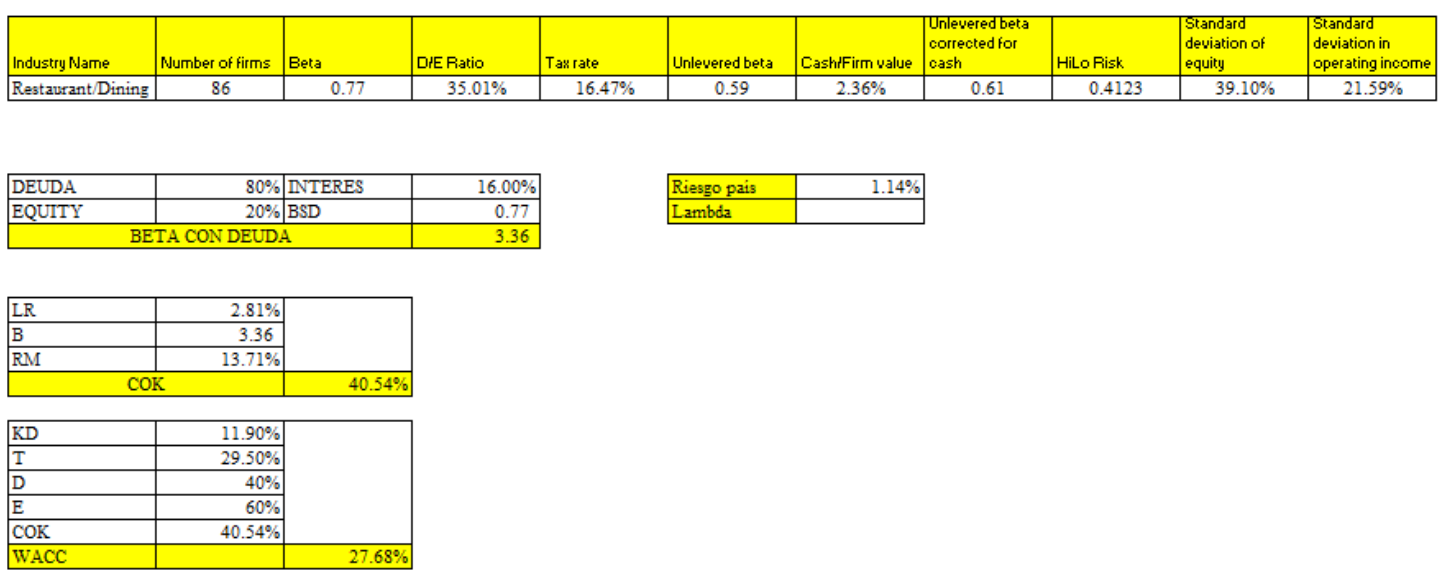

Elaboración propia.

\subsection{Análisis por escenarios y gráficas}


Tabla 7.17

Punto de equilibrio

\begin{tabular}{|c|lr|}
\hline COSTO VARIABLE & \multicolumn{2}{|c|}{ S/. } \\
\hline COSTO TAMAL UNITARIO & S/. & 3.05 \\
\hline SUMINISTROS COMBO & S/. & 1.39 \\
\hline TOTAL C.V.U. TAMAL & S/. & 4.44 \\
\hline
\end{tabular}

\begin{tabular}{|l|r|}
\hline UNIDADES VENDIDAS DE TAMAL & $1,889.00$ \\
\hline
\end{tabular}

\begin{tabular}{|c|c|}
\hline \multicolumn{1}{|c|}{ COSTO FLJO } & S/. \\
\hline MANO DE OBRA & S/. $19,470.00$ \\
\hline ALQUILER & S/. $33,333.33$ \\
\hline TOTAL COSTO FLJO & S/. $52,803.33$ \\
\hline
\end{tabular}

\begin{tabular}{|c|cc|}
\hline INGRESOS UNITARIOS & \multicolumn{2}{|c|}{ S/. } \\
\hline PRECIO UNITARIO TAMAL & S/. & 10.93 \\
\hline
\end{tabular}

\begin{tabular}{|c|r|}
\hline INGRESO TOTAL TAMAL & $20,650.93$ \\
\hline INGRESO TOTAL & $20,650.93$ \\
\hline
\end{tabular}

\begin{tabular}{|c|r|}
\hline COSTO TOTAL VARLABLE & $8,388.97$ \\
\hline COSTO TOTAL FIJO & S/. 52,803.33 \\
\hline COSTO TOTAL & $61,192.31$ \\
\hline
\end{tabular}

Elaboración propia.

Figura 7.1

Punto de equilibrio

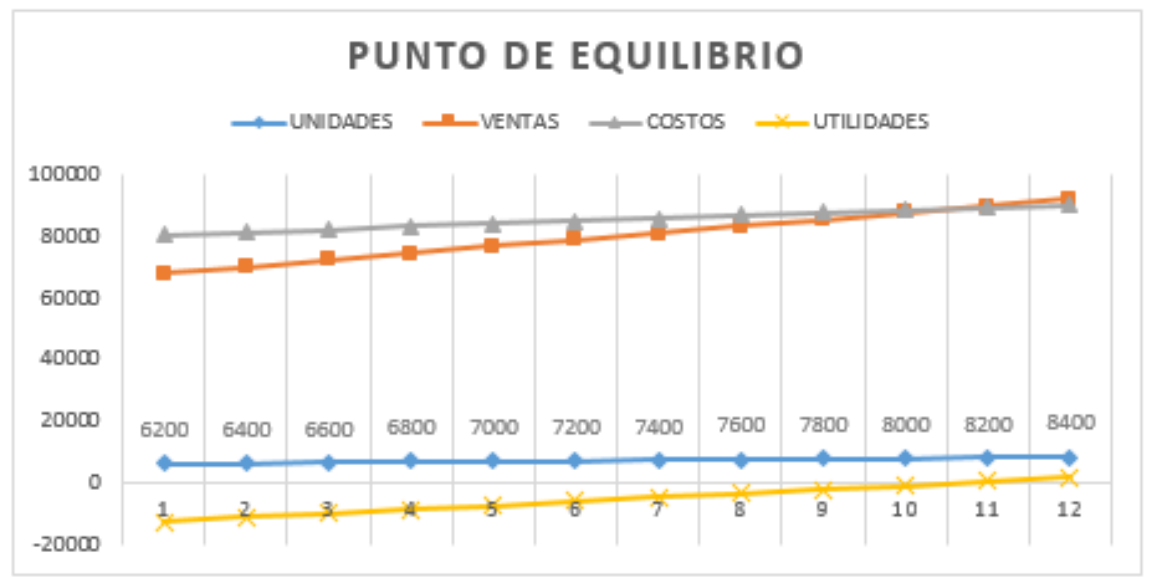

Elaboración propia.

Escenario pesimista: las ventas caen a un $50 \%$ ante la entrada de un nuevo competidor. 
Tabla 7.18

Flujo proyectado en escenario pesimista

\begin{tabular}{|c|c|c|c|c|c|c|c|c|c|c|c|c|}
\hline \multirow[b]{2}{*}{ INVERSION INICIAL } & \multicolumn{12}{|c|}{ PERIODO DE TIEMPO EXPRESADO EN AÑOS } \\
\hline & \multicolumn{3}{|c|}{0} & 1 & \multicolumn{2}{|c|}{2} & \multicolumn{2}{|c|}{3} & \multicolumn{2}{|r|}{4} & \multicolumn{2}{|r|}{5} \\
\hline EQUIPAMENTO & $\mathrm{S} /$. & $83,423.73$ & & & & & & & & & & \\
\hline ESTRUCTURAS & $\mathrm{S} /$. & $135,593.22$ & & & & & & & & & & \\
\hline INTANGIBLES & $\mathrm{S} /$. & $4,990.00$ & & & & & & & & & & \\
\hline CAPITAL DE TRABAJO & $\mathrm{S} /$. & $75,566.89$ & & & & & & & & & & \\
\hline $\begin{array}{l}\text { TOTAL INVERSION } \\
\end{array}$ & $\mathrm{S} /$. & $299,573.84$ & $\mathrm{~S} /$. & - & S/. & - & $\mathrm{S} /$. & - & $\mathrm{S} /$. & - & $\mathrm{S} /$. & - \\
\hline INGRESOS & & & & 2,018 & & 2,019 & & 2,020 & & 2,021 & & 2,022 \\
\hline VENTAS COMBOSS TAMALEATE & & & $\mathrm{S} /$. & $918,305.08$ & S/. & $991,769.49$ & $\mathrm{~S} /$. & $892,592.54$ & $\mathrm{~S} /$. & $883,666.62$ & $\mathrm{~S} /$. & $839,483.29$ \\
\hline $\begin{array}{l}\text { TOTAL INGRESOS } \\
\end{array}$ & & & $\mathrm{S} /$. & $918,305.08$ & $\mathrm{~S} /$. & $991,769.49$ & $\mathrm{~S} /$. & $892,592.54$ & $\mathrm{~S} /$. & $883,666.62$ & $\mathrm{~S} /$. & $839,483.29$ \\
\hline \multicolumn{13}{|l|}{ EGRESOS } \\
\hline \multicolumn{13}{|l|}{ costos } \\
\hline COSTO TAMALES TAMALEATE & & & $\mathrm{S} /$. & $256,271.19$ & $\mathrm{~S} /$. & $276,772.88$ & $\mathrm{~S} /$. & $249,095.59$ & $\mathrm{~S} /$. & $246,604.64$ & $\mathrm{~S} /$. & $234,274.41$ \\
\hline SUMINISTROS & & & $\mathrm{S} /$. & $168,251.09$ & $\mathrm{~S} /$. & $201,901.30$ & $\mathrm{~S} /$ & $222,091.43$ & $\mathrm{~S} /$. & $244,300.58$ & $\mathrm{~S} /$. & $268,730.63$ \\
\hline FIJO ALQUILER & & & $-\mathrm{S} /$ & $100,000.00$ & $\mathrm{~S} /$. & - & $\mathrm{S} /$. & - & $\mathrm{S} /$. & - & $\mathrm{S} /$. & - \\
\hline TOTAL COSTOS & $\mathrm{S} /$. & - & $\mathrm{S} /$. & $324,522.27$ & $\mathrm{~S} /$. & $478,674.18$ & $\mathrm{~S} /$. & $471,187.03$ & $\mathrm{~S} /$. & $490,905.21$ & $\mathrm{~S} /$. & $503,005.04$ \\
\hline \multicolumn{13}{|l|}{ GASTOS } \\
\hline RRHH & & & $\mathrm{S} /$. & $214,170.00$ & $\mathrm{~S} /$. & $233,640.00$ & $\mathrm{~S} /$. & $233,640.00$ & S/. & $233,640.00$ & $\mathrm{~S} /$. & $233,640.00$ \\
\hline$I \& D$ & & & $\mathrm{~S} /$. & $36,732.20$ & $\mathrm{~S} /$. & $39,670.78$ & $\mathrm{~S} /$. & $35,703.70$ & $\mathrm{~S} /$. & $35,346.66$ & $\mathrm{~S} /$. & $33,579.33$ \\
\hline GASTO DE VENTAS & & & $\mathrm{S} /$. & $13,200.00$ & $\mathrm{~S} /$. & $13,200.00$ & $\mathrm{~S} /$. & $13,200.00$ & $\mathrm{~S} /$. & $13,200.00$ & $\mathrm{~S} /$. & $13,200.00$ \\
\hline GASTO FINANCIERO & & & $\mathrm{S} /$. & $47,302.73$ & $\mathrm{~S} /$. & $54,871.16$ & $\mathrm{~S} /$. & $63,650.55$ & $\mathrm{~S} /$. & $73,834.64$ & $\mathrm{~S} /$. & - \\
\hline INTERES PAGADO & & & $\mathrm{S} /$. & $32,640.03$ & $\mathrm{~S} /$. & $25,071.59$ & $\mathrm{~S} /$. & $16,292.21$ & $\mathrm{~S} /$. & $6,108.12$ & $\mathrm{~S} /$. & - \\
\hline OTROS GASTOS & & & $\mathrm{S} /$. & $9,183.05$ & $\mathrm{~S} /$. & $9,917.69$ & $\mathrm{~S} /$. & $8,925.93$ & $\mathrm{~S} /$. & $8,836.67$ & $\mathrm{~S} /$. & $8,394.83$ \\
\hline DEPRECIACION & & & $\mathrm{S} /$. & $42,013.56$ & $\mathrm{~S} /$. & $42,013.56$ & $\mathrm{~S} /$. & $42,013.56$ & $\mathrm{~S} /$. & $42,013.56$ & $\mathrm{~S} /$. & $42,013.56$ \\
\hline $\begin{array}{l}\text { TOTAL GASTOS } \\
\end{array}$ & $\mathrm{S} /$. & - & $\mathrm{S} /$. & $395,241.57$ & $\mathrm{~S} /$. & $418,384.79$ & $\mathrm{~S} /$. & $413,425.94$ & $\mathrm{~S} /$. & $412,979.64$ & $\mathrm{~S} /$. & $330,827.72$ \\
\hline $\begin{array}{l}\text { TOTAL EGRESOS } \\
\end{array}$ & $\mathrm{S} /$. & - & S/. & $719,763.84$ & $\mathrm{~S} /$. & $897,058.97$ & $\mathrm{~S} /$. & $884,612.97$ & S/. & $903,884.86$ & $\mathrm{~S} /$. & $833,832.76$ \\
\hline $\begin{array}{l}\text { FLUJO OPERATIVO } \\
\end{array}$ & & & S/. & $198,541.25$ & $\mathrm{~S} /$. & $94,710.52$ & $\mathrm{~S} /$. & $\begin{array}{l}7,979.58 \\
\end{array}$ & $-\mathrm{S} /$. & $20,218.24$ & $\mathrm{~S} /$. & $5,650.52$ \\
\hline IR & & & $-\mathrm{S} /$ & $58,569.67$ & $-\mathrm{S} /$. & $27,939.60$ & $-\mathrm{S} /$ & $2,353.97$ & $\mathrm{~S} /$. & $5,964.38$ & $-\mathrm{S} /$. & $1,666.90$ \\
\hline & & & $\mathrm{S} /$ & $42,013.56$ & S/. & $42,013.56$ & $\mathrm{~S} /$. & $42,013.56$ & S/. & $42,013.56$ & $\mathrm{~S} /$. & $42,013.56$ \\
\hline INVERSION & $\mathrm{S} /$ & $299,573.84$ & & & & & & & $\mathrm{~S} /$. & - & & \\
\hline CAPITAL DE TRABAJO & & & & & & & & & & & $\mathrm{S} /$. & $75,566.89$ \\
\hline FLUJO DE CAJA FINANCIERO & $-\mathrm{S} /$. & $299,573.84$ & $\mathrm{~S} /$. & $181,985.14$ & $\mathrm{~S} /$. & $108,784.48$ & $\mathrm{~S} /$. & $47,639.16$ & S/. & $27,759.70$ & $\mathrm{~S} /$. & $121,564.07$ \\
\hline
\end{tabular}

Elaboración propia.

Escenario positivo: se reactiva la mega tendencia de consumir productos y junto a la mega tendencia de Perú destino gastronómico del mundo, nuestras ventas aumentan en un $25 \%$.

Tabla 7.19

Flujo proyectado en escenario optimista 


\begin{tabular}{|c|c|c|c|c|c|c|c|c|c|c|c|c|}
\hline \multirow[b]{2}{*}{ INVERSION INICIAL } & \multicolumn{12}{|c|}{ PERIODO DE TIEMPO EXPRESADO EN AÑOS } \\
\hline & \multicolumn{2}{|r|}{0} & \multicolumn{2}{|r|}{1} & \multicolumn{2}{|r|}{2} & \multicolumn{2}{|r|}{3} & \multicolumn{2}{|r|}{4} & \multicolumn{2}{|r|}{5} \\
\hline EQUIPAMENTO & $\mathrm{S} /$. & $83,423.73$ & & & & & & & & & & \\
\hline ESTRUCTURAS & $\mathrm{S} /$. & $135,593.22$ & & & & & & & & & & \\
\hline INTANGIBLES & $\mathrm{S} /$. & $4,990.00$ & & & & & & & & & & \\
\hline CAPITAL DE TRABAJO & $\mathrm{S} /$. & $75,566.89$ & & & & & & & & & & \\
\hline TOTAL INVERSION & $\mathrm{S} /$. & $299,573.84$ & $\mathrm{~S} /$. & - & $\mathrm{S} /$. & - & $\mathrm{S} /$. & - & S/. & - & S/. & - \\
\hline INGRESOS & & & & 2,018 & & 2,019 & & 2,020 & & 2,021 & & 2,022 \\
\hline VENTAS COMBOSS TAMALEATE & & & $\mathrm{S} /$. & $1,357,779.66$ & $\mathrm{~S} /$. & $1,549,342.37$ & $\mathrm{~S} /$. & $1,788,703.67$ & $\mathrm{~S} /$. & $2,049,005.29$ & $\mathrm{~S} /$. & $2,347,151.57$ \\
\hline TOTAL INGRESOS & & & $\mathrm{S} /$. & $1,357,779.66$ & $\mathrm{~S} /$. & $1,549,342.37$ & $\mathrm{~S} /$. & $1,788,703.67$ & $\mathrm{~S} /$. & $2,049,005.29$ & $\mathrm{~S} /$. & $2,347,151.57$ \\
\hline \multicolumn{13}{|l|}{ EGRESOS } \\
\hline \multicolumn{13}{|l|}{ COSTOS } \\
\hline COSTO TAMALES TAMALEATE & & & $\mathrm{S} /$. & $378,915.25$ & $\mathrm{~S} /$. & $411,544.07$ & $\mathrm{~S} /$. & $459,355.81$ & $\mathrm{~S} /$. & $512,251.32$ & $\mathrm{~S} /$. & $570,679.99$ \\
\hline SUMINISTROS & & & $\mathrm{S} /$. & $168,251.09$ & $\mathrm{~S} /$. & $201,901.30$ & $\mathrm{~S} /$. & $222,091.43$ & $\mathrm{~S} /$. & $244,300.58$ & $\mathrm{~S} /$. & $268,730.63$ \\
\hline FIJO ALQUILER & & & $-\mathrm{S} /$ & $100,000.00$ & $\mathrm{~S} /$. & - & $\mathrm{S} /$. & - & $\mathrm{S} /$. & - & S/. & - \\
\hline TOTAL COSTOS & $\mathrm{S} /$. & - & $\mathrm{S} /$. & $447,166.34$ & $\mathrm{~S} /$. & $613,445.37$ & $\mathrm{~S} /$. & $681,447.24$ & $\mathrm{~S} /$. & $756,551.90$ & $\mathrm{~S} /$. & $839,410.62$ \\
\hline \multicolumn{13}{|l|}{ GASTOS } \\
\hline RRHH & & & $\mathrm{S} /$. & $214,170.00$ & $\mathrm{~S} /$. & $233,640.00$ & $\mathrm{~S} /$. & $233,640.00$ & $\mathrm{~S} /$. & $233,640.00$ & $\mathrm{~S} /$. & $233,640.00$ \\
\hline $\mathrm{I} \& \mathrm{D}$ & & & $\mathrm{S} /$. & $54,311.19$ & $\mathrm{~S} /$. & $61,973.69$ & $\mathrm{~S} /$. & $71,548.15$ & $\mathrm{~S} /$. & $81,960.21$ & $\mathrm{~S} /$. & $93,886.06$ \\
\hline GASTO DE VENTAS & & & $\mathrm{S} /$. & $13,200.00$ & $\mathrm{~S} /$. & $13,200.00$ & $\mathrm{~S} /$. & $13,200.00$ & $\mathrm{~S} /$. & $13,200.00$ & $\mathrm{~S} /$. & $13,200.00$ \\
\hline GASTO FINANCIERO & & & $\mathrm{S} /$. & $47,302.73$ & $\mathrm{~S} /$. & $54,871.16$ & $\mathrm{~S} /$. & $63,650.55$ & $\mathrm{~S} /$. & $73,834.64$ & $\mathrm{~S} /$. & - \\
\hline INTERES PAGADO & & & $\mathrm{S} /$. & $32,640.03$ & $\mathrm{~S} /$. & $25,071.59$ & $\mathrm{~S} /$. & $16,292.21$ & $\mathrm{~S} /$. & $6,108.12$ & $\mathrm{~S} /$. & - \\
\hline OTROS GASTOS & & & $\mathrm{S} /$. & $13,577.80$ & $\mathrm{~S} /$. & $15,493.42$ & $\mathrm{~S} /$. & $17,887.04$ & $\mathrm{~S} /$. & $20,490.05$ & $\mathrm{~S} /$. & $23,471.52$ \\
\hline DEPRECIACION & & & $\mathrm{S} /$. & $42,013.56$ & $\mathrm{~S} /$. & $42,013.56$ & $\mathrm{~S} /$. & $42,013.56$ & $\mathrm{~S} /$. & $42,013.56$ & S/. & $42,013.56$ \\
\hline TOTAL GASTOS & $\mathrm{S} /$. & - & $\mathrm{S} /$. & $417,215.30$ & $\mathrm{~S} /$. & $446,263.43$ & $\mathrm{~S} /$. & $458,231.50$ & $\mathrm{~S} /$. & $471,246.58$ & $\mathrm{~S} /$. & $406,211.14$ \\
\hline $\begin{array}{l}\text { TOTAL EGRESOS } \\
\end{array}$ & $\mathrm{S} /$. & - & $\mathrm{S} /$. & $864,381.64$ & $\mathrm{~S} /$. & $1,059,708.80$ & $\mathrm{~S} /$. & $1,139,678.73$ & S/. & $1,227,798.48$ & $\mathrm{~S} /$. & $1,245,621.76$ \\
\hline $\begin{array}{l}\text { FLUJO OPERATIVO } \\
\end{array}$ & & & S/. & $493,398.03$ & $\mathrm{~S} /$. & $489,633.57$ & $\mathrm{~S} /$. & $649,024.93$ & $\mathrm{~S} /$. & $821,206.81$ & S/. & $1,101,529.80$ \\
\hline \multirow[t]{2}{*}{ IR } & & & $-\mathrm{S} /$ & $145,552.42$ & $-\mathrm{S} /$ & $144,441.90$ & $-\mathrm{S} /$ & $191,462.35$ & $-\mathrm{S} /$ & $242,256.01$ & $-\mathrm{S} /$ & $324,951.29$ \\
\hline & & & $\mathrm{S} /$. & $42,013.56$ & $\mathrm{~S} /$. & $42,013.56$ & $\mathrm{~S} /$. & $42,013.56$ & $\mathrm{~S} /$. & $42,013.56$ & $\mathrm{~S} /$. & $42,013.56$ \\
\hline INVERSION & $\mathrm{S} /$. & $299,573.84$ & & & & & & & $\mathrm{~S} /$. & - & & \\
\hline CAPITAL DE TRABAJO & & & & & & & & & & & S/. & $75,566.89$ \\
\hline FLUJO DE CAJA FINANCIERO & $-\mathrm{S} / \mathrm{s}$ & $299,573.84$ & $\mathrm{~S} /$. & $389,859.17$ & $\mathrm{~S} /$. & $387,205.23$ & S/. & $499,576.14$ & S/. & $620,964.36$ & $\mathrm{~S} /$. & $894,158.96$ \\
\hline
\end{tabular}

Elaboración propia.

\subsection{Principales riesgos del proyecto (cualitativos)}

- Ingreso de potenciales competidores.

- Aumento del costo de los tamales por el incremento del precio en insumos debido a fenómenos naturales.

- Mal manejo de quejas, el cual generaría un impacto negativo en redes sociales.

- Falla del proveedor principal dejando desabastecido el restaurante.

\subsection{Plan de contingencia y disolución}

"Tamaléate" cuenta con dos tipos de contingencias: la primera es ante una compra imprevista por parte de algún inversionista; de ser este el caso "Tamaléate" valorizará la 
cuota del mercado y la llevará a valor futuro en un periodo de 10 años considerando que cada año la cuota de mercado aumentará entre un 5\% y $15 \%$.

El segundo caso es que "Tamaléate" no cumple con la cuota del mercado y por ende no llega al punto de equilibrio; de ser este el caso "Tamaléate" cerrará operaciones y liquidará todos los activos en caso se diera durante el primer año el valor de recuperación está estimado en un $80 \%$ del capital invertido. 


\section{CONCLUSIONES Y RECOMENDACIONES}

- "Tamaléate" es un nuevo concepto de stand up restaurant que está orientado al público criollo lover que busca satisfacer la necesidad de comer un producto nuevo pero que a su vez tiene tradición.

- "Tamaléate" es un emprendimiento que se crea para repotenciar el consumo de tamal, gracias a la fusión de sabores.

- "Tamaléate" es un negocio viable pues cuenta con buenos indicadores financieros.

- "Tamaléate" es un modelo escalable ya que permite abrir más sucursales en cualquier punto de la ciudad; cabe resaltar que el producto tiene la característica de que puede ser consumido por cualquier nivel socio económico; el único requisito es que te provoque comer un tamal.

- "Tamaléate" retribuye a la comunidad pues donará los productos que no se consuman en el día a REMAR que es el ente encargado de distribuir estos productos de manera gratuita a personas con bajos recursos económicos.

- "Tamaléate" desarrollará el proyecto denominado "Tamal para todos" que consistirá en brindar orientación y capacitación a las comercializadoras informales de tamal (tamaleras de esquina). Dichas capacitaciones estarán compuestas por los siguientes módulos: calidad, atención al cliente, costos y operación con el fin de que ellas puedan repotenciar su modelo de negocio obteniendo mayores beneficios y en un mediano plazo puedan formar parte de la cadena de valor de "Tamaléate". 


\section{REFERENCIAS}

BOLADO, Victoria y otros

2010 Ácidos grasos trans de la dieta y sus implicaciones metabólicas. En Gaceta Médica de México. México DF, volumen 146, número 4, pp.281-288. Consulta 24 de Julio de 2017.

http://www.medigraphic.com/pdfs/gaceta/gm-2010/gm104f.pdf

CHAPARRO, Claudio.

2008 Irresistible tamal. La República. Consulta: 16 de Agosto de 2017. http://larepublica.pe/archivo/367323-irresistible-tamal

\section{CONGRESO DE LA REPÚBLICA}

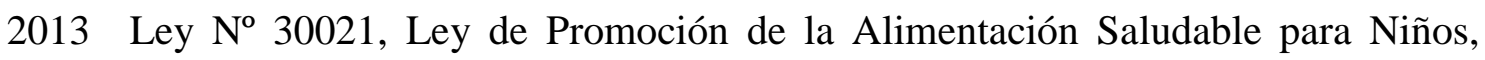
Niñas y Adolescentes. Lima, 17 de Mayo. Consulta: 16 de Agosto de 2017. http://busquedas.elperuano.pe/normaslegales/ley-de-promocion-de-laalimentacion-saludable-para-ninos-ni-ley-n-30021-938532-1/

PATIÑN, Germán

2006 El tamal. Semana de Colombia. Consulta: 21 de Agosto http://www.semana.com/on-line/articulo/el-tamal/82803-3

\section{REAL ACADEMIA ESPAÑOLA(RAE)}

2014 Diccionario de la lengua española. Vigésima tercera edición. Madrid:España. Consulta: 24 de Julio de 2017. http://dle.rae.es/?id=Z1mIKpQ 
INSTITUTO NACIONAL DE ESTADÍSTICA E INFORMÁTICA (INEI)

2015 Al 30 de Junio del 2015 el Perú tiene 31 millones 151 mil 643 habitantes. Lima.

$\begin{array}{llllll}\text { Consulta: } & 16 & \text { de } & \text { Junio } & \text { de } & \end{array}$

https://www.inei.gob.pe/prensa/noticias/al-30-de-junio-de-2015-el-peru-tiene-

31-millones-151-mil-643-habitantes-8500/ 
ANEXOS 


\section{ANEXO 1: Matriz EFI}

\begin{tabular}{|l|l|l|l|l|}
\hline \multicolumn{2}{|l}{ MATRIZ EFI } & Valor & Clasificación & Valor Ponderado \\
\hline 1 & F1 Vartalezas de sabores & $9 \%$ & 4 & 0.36 \\
\hline 2 & F2 No contiene grasas saturadas ni grasas trans & $8 \%$ & 4 & 0.32 \\
\hline 3 & F3 Listo para consumir & $6 \%$ & 4 & 0.24 \\
\hline 4 & F4 No hay línea de producción & $6 \%$ & 3 & 0.18 \\
\hline 5 & F5 Buena calidad del producto & $8 \%$ & 3 & 0.24 \\
\hline 6 & F6 Es un producto innovador en el mercado & $8 \%$ & 4 & 0.32 \\
\hline 7 & F7 Producto con el sello marca Perú & $6 \%$ & 3 & 0.18 \\
\hline 8 & F8 Nueva propuesta de alimentación al paso & $6 \%$ & 3 & 0.18 \\
\hline 9 & F9 Nuevo concepto de restaurante stand up & $8 \%$ & 3 & 0.24 \\
\hline
\end{tabular}




\begin{tabular}{|l|l|l|l|l|}
1 & D1 Falta de publicidad & $9 \%$ & 2 & 0.18 \\
\hline 2 & D2 Marca no conocida por los segmentos medios & $6 \%$ & 1 & 0.06 \\
\hline 3 & D3 Un solo tamaño de presentación & $4 \%$ & 2 & 0.08 \\
\hline 4 & D4 Recursos económicos limitados & $8 \%$ & 1 & 0.08 \\
\hline 5 & D5 Cartera de productos limitada & $8 \%$ & 1 & 0.08 \\
\hline & Total & $\mathbf{1 0 0 \%}$ & $\mathbf{2 . 7 4}$ \\
\hline
\end{tabular}




\section{ANEXO 2: Matriz EFE}

\begin{tabular}{|l|l|l|l|l|}
\hline \multicolumn{2}{|l|}{ Matriz EFE } & Valor & Clasificación & Valor Ponderado \\
\hline 1 & O1 Mayor poder adquisitivo & $8 \%$ & 3 & 0.24 \\
\hline 2 & O2 Aumento del empleo & $7 \%$ & 3 & 0.198 \\
\hline 3 & O3 Mayores diversidad de canales de comunicación & $8 \%$ & 4 & 0.32 \\
\hline 4 & O4 Mayor vías de acceso al interior & $5 \%$ & 3 & 0.15 \\
\hline 5 & O5 Mayor cantidad de TLC & $5 \%$ & 2 & 0.1 \\
\hline 6 & O6 Tiempo limitado & $8 \%$ & 4 & 0.32 \\
\hline 7 & O7 Tendencia a no consumir grasas saturadas ni grasas trans & $8 \%$ & 4 & 0.32 \\
\hline 8 & O8 Tendencia a consumir los productos peruanos & $7 \%$ & 4 & 0.264 \\
\hline 9 & O9 Nuevas técnicas de regadío & $5 \%$ & 2 & - \\
\hline
\end{tabular}




\begin{tabular}{|c|c|c|c|c|}
\hline \multicolumn{5}{|c|}{ Amenazas } \\
\hline 1 & A1 Precio de combustible & $8 \%$ & 1 & 0.08 \\
\hline 2 & A2 Inestabilidad política & $6 \%$ & 2 & 0.12 \\
\hline 3 & A3 Fenómenos climáticos inesperados & $7 \%$ & 1 & 0.066 \\
\hline 4 & A4 Alta competencia en el mercado & $7 \%$ & 2 & 0.132 \\
\hline 5 & A5 Es un producto del tipo elástico & $6 \%$ & 2 & 0.12 \\
\hline 6 & A6 Plagio de receta y / o producto & $7 \%$ & 1 & 0.066 \\
\hline & Total & $100 \%$ & & 2.60 \\
\hline
\end{tabular}




\section{ANEXO 3: Variables de macro entorno}

\begin{tabular}{|c|c|c|c|}
\hline Variables políticas & & & \\
\hline Evento o Fuerza & Prob. & Efecto & $\mathrm{O} / \mathrm{A}$ \\
\hline Política de impuestos & $75 \%$ & $\begin{array}{l}\text { Afecta directamente al consumidor por } \\
\text { ende a la empresa pues va a modificar el } \\
\text { precio de }\end{array}$ & $\mathrm{O} / \mathrm{A}$ \\
\hline Políticas salariales & $50 \%$ & $\begin{array}{l}\text { Afecta a los recursos económicos de la } \\
\text { empresa y a su vez hará que se } \\
\text { modifiquen las proyecciones destinadas } \\
\text { a la mano de obra. }\end{array}$ & A \\
\hline Inestabilidad política & $100 \%$ & $\begin{array}{l}\text { Modificación y derogación de leyes que } \\
\text { afecten directamente al consumidor o al } \\
\text { micro empresario. }\end{array}$ & $\mathrm{O} / \mathrm{A}$ \\
\hline Elecciones municipales 2018 & $100 \%$ & $\begin{array}{l}\text { Creación de nuevos regímenes o barreras } \\
\text { de entrada en el municipio. }\end{array}$ & A \\
\hline
\end{tabular}




\begin{tabular}{|c|c|c|c|}
\hline Variables económicas & & & \\
\hline Evento o Fuerza & Prob. & Efecto & $\mathrm{O} / \mathrm{A}$ \\
\hline PBI & $100 \%$ & $\begin{array}{l}\text { El crecimiento económico per capita de } \\
\text { nuestros consumidores, lo cual permitirá } \\
\text { que tenga mayor disposición de dinero } \\
\text { para gastar. }\end{array}$ & $\mathrm{O} / \mathrm{A}$ \\
\hline $\begin{array}{l}\% \text { de población } \\
\text { económicamente activa }\end{array}$ & $80 \%$ & $\begin{array}{l}\text { Forma parte de nuestro mercado objetivo } \\
\text { y la probabilidad de crecimiento del } \\
\text { mercado del negocio. }\end{array}$ & $\mathrm{O} / \mathrm{A}$ \\
\hline Tasas de interés \% & $50 \%$ & $\begin{array}{l}\text { Si la tasa baja nuestra moneda se devalúa } \\
\text { e impacta en el consumo de los clientes }\end{array}$ & A \\
\hline Inflación & $100 \%$ & $\begin{array}{l}\text { La devaluación de la moneda impacta de } \\
\text { manera negativa pues la pérdida de valor } \\
\text { hará que el mercado optimice sus gastos } \\
\text { y no se vea. }\end{array}$ & A \\
\hline
\end{tabular}




\begin{tabular}{|c|c|c|c|}
\hline Variables socio culturales & & & \\
\hline Evento o Fuerza & Prob. & Efecto & $\mathrm{O} / \mathrm{A}$ \\
\hline $\begin{array}{l}\text { Mega tendencia de no consumo } \\
\text { de grasas saturadas y grasas } \\
\text { trans }\end{array}$ & $100 \%$ & $\begin{array}{l}\text { Esta tendencia genera un mercado } \\
\text { potencial de personas que obtan por } \\
\text { comer cosas de buen sabor contundentes } \\
\text { y que no sean dañinas. }\end{array}$ & $\mathrm{O}$ \\
\hline $\begin{array}{l}\text { Tendencia de consumo de } \\
\text { producto nacional }\end{array}$ & $100 \%$ & $\begin{array}{l}\text { El nacionalismo es una tendencia que } \\
\text { viene creciendo año a año y que impacta } \\
\text { directamente en todos los negocios que } \\
\text { tienen capital nacional. }\end{array}$ & $\mathrm{O}$ \\
\hline $\begin{array}{l}\text { Mega tendencia de comida } \\
\text { peruana y fusión del mundo }\end{array}$ & $100 \%$ & $\begin{array}{l}\text { Hoy la comida peruana es considerada la } \\
\text { mejor del mundo es por eso que el tema } \\
\text { de fusión de sabores se compenetra con } \\
\text { está, convocando a mayor cantidad de } \\
\text { clientes y consumidores. }\end{array}$ & $\mathrm{O}$ \\
\hline $\begin{array}{l}\text { Tiempo limitado en la vida } \\
\text { cotidiana de las personas }\end{array}$ & $100 \%$ & $\begin{array}{l}\text { El no tener tiempo para poder } \\
\text { alimentarnos es una oportunidad de } \\
\text { negocio, el cual beneficia directamente al } \\
\text { negocio }\end{array}$ & $\mathrm{O}$ \\
\hline
\end{tabular}




\begin{tabular}{|l|l|l|l|}
\hline Variable tecnológica & \multicolumn{3}{|l|}{} \\
\hline Evento o Fuerza & Prob. & Efecto & O/A \\
\hline $\begin{array}{l}\text { Nuevas tecnologías aplicadas a } \\
\text { la restauración }\end{array}$ & $50 \%$ & $\begin{array}{l}\text { Facilitación y automatización de procesos } \\
\text { que generan más eficiencia en la } \\
\text { operación. }\end{array}$ & O \\
\hline
\end{tabular}

\begin{tabular}{|c|c|c|c|c|}
\hline \multicolumn{2}{|l|}{ Variables ecológicas } & \multirow[b]{2}{*}{ Prob. } & \multirow[b]{2}{*}{ Efecto } & \multirow[b]{2}{*}{$\mathrm{O} / \mathrm{A}$} \\
\hline Evento o Fuerza & & & & \\
\hline Fenómeno del niño & & $75 \%$ & $\begin{array}{l}\text { Impacta negativamente en los costos de } \\
\text { la materia prima. }\end{array}$ & A \\
\hline $\begin{array}{l}\text { Cambio climático } \\
\text { contaminación }\end{array}$ & $\mathrm{y}$ & $75 \%$ & $\begin{array}{l}\text { Genera que las formas de cosecha y } \\
\text { siembra varíen, esto podría generar } \\
\text { incremento en costo y a su vez cambio de } \\
\text { sabores. }\end{array}$ & A \\
\hline Conciencia por el reciclaje & & $50 \%$ & $\begin{array}{l}\text { Desperdicios brandeados pueden generar } \\
\text { mala imagen }\end{array}$ & A \\
\hline
\end{tabular}




\begin{tabular}{|c|c|c|c|}
\hline Variable legal & & & \\
\hline Evento o Fuerza & Prob. & Efecto & $\mathrm{O} / \mathrm{A}$ \\
\hline Nuevas regulaciones de digesa & & $\begin{array}{l}\text { Las nuevas regulaciones podrán ejercer } \\
\text { mayor presión y búsqueda de excelencia } \\
\text { en las operaciones lo cual genera costos } \\
\text { ocultos. }\end{array}$ & A \\
\hline
\end{tabular}

